\title{
Química mineral de micas do maciço granítico Serra Branca, Goiás: processos de alteração hidrotermal como modificadores do reequilíbrio cristaloquímico
}

\author{
Cristina Valle Pinto-Coelho ${ }^{1}$, Eleonora Maria Gouvea Vasconcellos ${ }^{2}$ \& \\ Carlos Henrique Nalin Ferreira ${ }^{3}$
}

\begin{abstract}
Resumo No Maciço Granítico da Serra Branca (MGSB), localizado na porção Norte do Estado de Goiás, ocorrem quatro fácies petrográficas, identificadas em função da intensidade dos processos hidrotermais responsáveis pela formação de greisens e de mineralização de cassiterita. São eles: a) granito rosa a cinza (g1a), inequigranular, porfiróide médio a grosso; aflorando na porção ocidental do maciço; b) granito cinza a róseo (g1b), inequigranular médio a grosso; c) granito cinza (g1c) inequigranular, médio a grosso e d) granito cinza (g1d) inequigranular, médio, ocorrendo na porção oriental do maciço. Ocorrem, ainda, greisens apicais e filões micáceos. As fácies graníticas são formadas por diferentes porcentagens de quartzo, biotita, mica branca, microclínio pertítico e albita, onde as porcentagens variam em função da intensidade da alteração hidrotermal. Os minerais acessórios são zircão, apatita, allanita, monazita e opacos (ilmenita). Os processos hidrotermais observados são albitização, greisenização e microclinização. Os greisens são compostos por quartzo e mica branca; ocorrem, ainda, em porcentagens variadas, topázio, fluorita, cassiterita, berilo, monazita, scheelita, grafita, esfalerita, zoisita, zircão, apatita, fenacita e opacos. A biotita é a única fase mineral ferromagnesiana presente no MGSB e não apresenta grandes disparidades químicas, projetando-se no domínio da composição da biotita associada à muscovita. Possui $\mathrm{Al}$ em posição octaédrica e é classificada como aluminosa. As fácies graníticas do MGSB contêm muscovita em quantidade e hábitos variáveis. Três tipos ou grupos petrográficos de micas brancas foram definidos: a) dos granitos (g1a), (g1b) e (g1c); b) do granito (g1d); e c) dos greisens e filões micáceos. As variações geoquímicas não são importantes e, assim como para a biotita, são mais marcantes no interior de um mesmo grupo do que entre as diferentes fácies observadas. Globalmente, as micas brancas são ferríferas, fracamente magnesianas e titaníferas, medianamente fluoretadas (F varia de 0,3 a 2,7\% em peso) e não litiníferas. A substituição fengítica (celadonítica) nas micas brancas do MGSB exprime-se de maneiras distintas: a) em porcentagens de celadonita pelo excesso de sílica em posição tetraédrica; b) visualizada no diagrama $\mathrm{Si}+\mathrm{M}^{2+}$ versus $\mathrm{Al}$ total $\left(\mathrm{Al}^{\mathrm{VI}}+\mathrm{Al}^{\mathrm{IV}}\right)$; c) estimada no diagrama $\mathrm{Al}^{\mathrm{VI}}+\mathrm{Al}^{\mathrm{IV}} / \mathrm{Fe}_{\mathrm{t}}$ (a.f.u.), que representa a parte do Fe na substituição fengítica. A substituição paragonítica encontra-se entre $2 \mathrm{e} 5 \%$. Em nenhuma das fácies graníticas, greisens ou filões micáceos associados ao MGSB foi identificada muscovita magmática.
\end{abstract}

Palavras-chave: micas, granito, hidrotermalismo, Província Estanífera de Goiás, química mineral

\begin{abstract}
Mineral chemistry of micas from the Serra Branca granitic massif-Goiás State-Brazil: hydrothermal alteration processes as modifiers of the crystalochemical reequilibrium. In the Serra Branca Granite (SBG) at Goiás State, Brazil, four petrographic facies are described according to the intensity of postmagmatic process forming greisen and cassiterite mineralization: a) pink to grey porphyroid granite (g1a); b) grey to pinkish, medium to coarse-grained inequigranular granite (g1b); c) grey, medium to coarsegrained inequigranular granite (g1c) and d) grey medium-grained inequigranular granite (g1d). Apical greisens and micaceous veins occur. The mineralogy includes quartz, biotite, white mica, perthitic microcline and albite. The acessory are zircon, apatite, allanite, monazite and opaques (ilmenite). Albitization, greisenization and microclinization are the postmagmatic phenomena. The greisens are composed of quartz and white mica; topaz, fluorite, cassiterite, beryl, monazite, scheelite, graphite, sphalerite, zoisite, zircon, apatite, phenakite and opaques. The biotite is the only ferromagnesian phase and is classified in the domain of biotite associated with muscovite. Muscovite occurs in varying quantities: as dominant or as the only mineral in the rock. Three types are defined: a) of (g1)a, (g1b) and (g1c) granites; b) of (g1d) granites; and c) of greisens and micaceous veins. The white micas are ferriferous, slightly magnesians and titaniferous, fluorous in median and not containing lithium. The phengitic (celadonitic) substitution is represented in a) percentages of celadonite due the excess of silica in tetrahedric position; b) $\mathrm{Si}+\mathrm{M}^{2}$ versus total $\mathrm{Al}$ diagram $\left(\mathrm{Al}^{\mathrm{VI}}+\mathrm{Al}^{\mathrm{IV}}\right)$; c) $\mathrm{Al}^{\mathrm{VI}}+\mathrm{Al}^{\mathrm{IV}} / \mathrm{Fe}_{\mathrm{t}}$ diagram (a.f.u.). The paragonitic substitution is between 2 and $5 \%$. In the illitic substitution a decrease of interlayered cations is accompanied with the growth of tetrahedric Si.
\end{abstract}

Keywords: micas, granite, hydrothermal alteration, Stanniferous Province from Goias, mineral chemistry.

1 - Departamento de Geologia, Universidade Federal do Paraná, Curitiba, PR, Brasil. E-mail: cristinavpc@ufpr.br

2 - Departamento de Geologia, Universidade Federal do Paraná, Curitiba, PR, Brasil. E-mail: eleonora@ufpr.br

3 - Acadêmico do Curso de Geologia, Universidade Federal do Paraná, Curitiba, PR, Brasil. E-mail: caique@ufpr.br 
INTRODUÇÃo Nos estados de Goiás e Tocantins, inúmeros depósitos de estanho relacionam-se a granitóides intraplaca paleo a mesoproterozóicos $(1,78$ a $1,57 \mathrm{Ga})$, ricos em F, Sn, Rb, Y, Th, Nb, Ga e ETR e com assinatura geoquímica compatível à de granitóides do tipo A. Essas rochas foram agrupadas em subprovíncias e englobadas na denominada Província Estanífera de Goiás (Marini \& Botelho 1986). O Maciço Granítico da Serra Branca (MGSB) hospeda mineralização de estanho, onde a cassiterita ligada aos greisens, descoberta em 1972, foi ativamente explorada até o início da década de 80 .

A porção Norte da Província Estanífera de Goiás, a mais importante em termos de mineralização de estanho, divide-se em duas subprovíncias: Rio Tocantins, a oeste, e Rio Paranã, a leste. O MGSB situa-se na subprovíncia Rio Tocantins e é intrusivo no embasamento do Cinturão de Dobramentos Brasília. Localiza-se no extremo Norte do Estado de Goiás, a aproximadamente $600 \mathrm{~km}$ de Brasília e a $22 \mathrm{~km}$ a SE do distrito de Minaçu, e limita-se pelos paralelos $13^{\circ} 33^{\prime} 45^{\prime \prime}$ e $13^{\circ} 38^{\prime} 50^{\prime \prime}$ de latitude S e pelos meridianos $48^{\circ} 07^{\prime} 13^{\prime \prime}$ e $48^{\circ} 05^{\prime} 34^{\prime \prime}$ de longitude W. Discussões geológicas e metalogenéticas sobre o maciço são encontradas em Pinto-Coelho (1996).

Micas de granitóides e de rochas hidrotermalizadas constituem excelentes indicadores da evolução magmática e pós-magmática responsáveis pela geração dessas rochas e de mineralizações a elas associadas, fornecendo parâmetros relativos às variáveis termodinâmicas vigentes durante o processo. Tal característica deve-se às múltiplas substituições observadas em função das condições de temperatura, $\mathrm{fO}_{2}$, pressão e do quimismo do meio de crescimento (Garcia \& Fonteilles 1985, Monier et al. 1987, Robert et al. 1993, Bray 1994). A análise da distribuição de elementos incompatíveis em micas fornece bons indicadores do comportamento desses elementos na rocha total e dos processos controladores da mineralização a eles associada (Barrière \& Cotten 1979; Fernandes et al. 2006). Indicadores geotectônicos são também obtidos a partir da análise de micas, sobretudo biotita (Abdel-Rahman 1994).

Neste trabalho são apresentados os dados relativos à química mineral das micas di e tri-octaédricas do MGSB, presentes em todos os tipos petrográficos aflorantes, e à atuação dos processos de alteração hidrotermal como modificadores do quimismo desses filossilicatos.

\section{O MACIÇO GRANÍTICO DA SERRA BRANCA} Aspectos petrográficos e litogeoquímicos O MGSB forma uma estrutura discretamente elíptica, com eixo maior direcionado $\mathrm{N} 15 \mathrm{~W}$, limitada por quartzitos subhorizontais atribuídos ao Grupo Araí, de idade paleoproterozóica (Fig. 1). O maciço encontra-se fortemente orientado, adquirindo, na parte E, uma xistosidade plana tangencial sub-horizontal.

Os quartzitos Araí formam uma coroa quase contínua ao longo de todo o corpo granítico, onde as al-

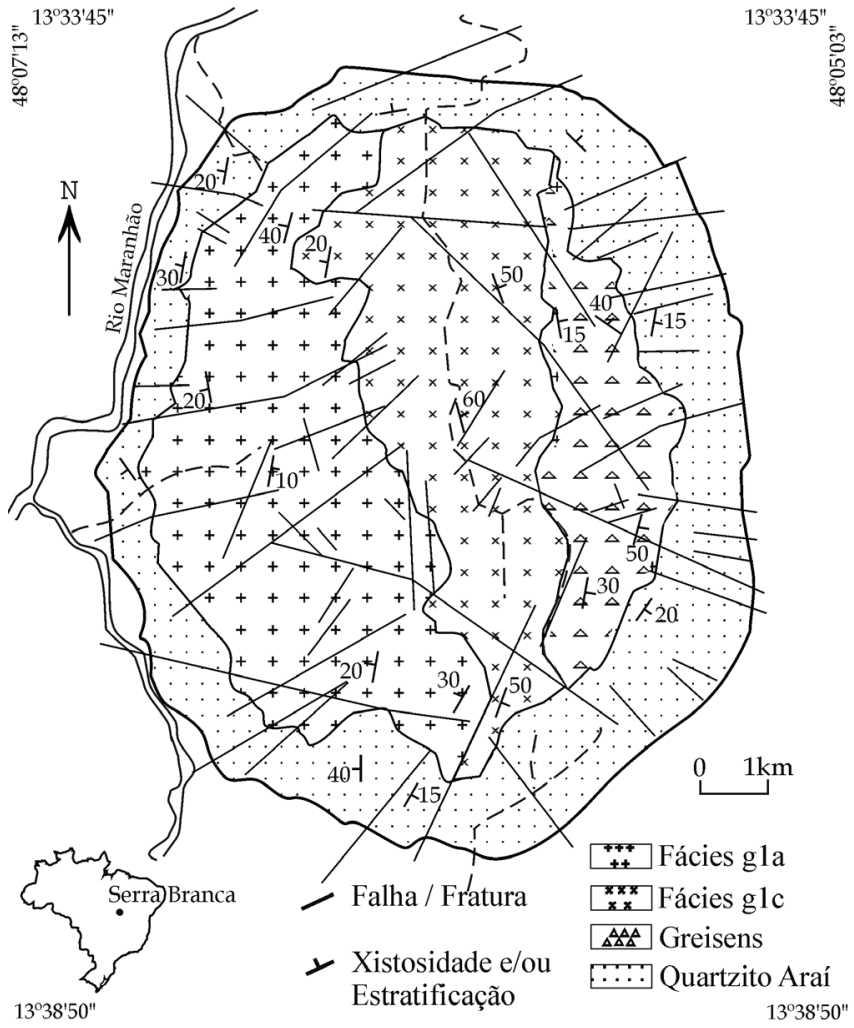

Figura 1 - Mapa geológico simplificado do Maciço Granítico Serra Branca e encaixantes (modificado de Andrade 1978). As fácies (glb) e (gld) não foram individualizadas por não possuirem dimensões mapeáveis na escala adotada.

titudes mais elevadas encontram-se nas bordas Leste e Sul. Apesar dessa morfologia particular, aparentemente invertida, a estruturação geral do conjunto é a de um domo perfeitamente circunscrito.

O fraturamento, com características anisótropas, faz-se por meio de fraturas dispostas ENE na parte ocidental do MGSB e NNE na sua porção oriental. O eixo maior do maciço dispõe-se N15W. Duas falhas maiores, sub-meridianas, interrompem a continuidade dos quartzitos na porção Sul. As falhas afetam indistintamente granitos, greisens e quartzitos, mas as estruturas maiores (NS e EW) afetam essencialmente o plúton, sem se prolongar na auréola quartzítica. O granito é fortemente estruturado até a aquisição de xistosidade planar tangencial sub-horizontal, como é o caso das fácies observadas na porção oriental do MGSB. Nenhuma estrutura semelhante é observada nos quartzitos, onde ainda se nota a presença de estruturas sedimentares (estratificação oblíqua); nenhum filão, nem apófise, são encontrados recortando a seqüência de quartzitos.

O exame macroscópico das rochas do MGSB revela a existência de variações petrográficas importantes, levando à definição de quatro fácies petrográficas distintas (Fig. 1): a) granito rosa a cinza (g1a), inequigranular, porfiróide médio a grosso; b) granito cinza a róseo (g1b), inequigranular médio a grosso; c) granito cinza (g1c) inequigranular, médio a grosso e d) granito cinza (g1d) inequigranular, médio, ocorrendo localiza- 
damente na porção oriental do maciço. Ocorrem, ainda, greisens apicais e filões micáceos. As fácies (g1b) e (g1d) não foram individualizadas no mapa geológico da figura 1 por não possuírem dimensões mapeáveis na escala adotada. Os dados modais distribuem-se, preferencialmente, no domínio 3 do diagrama QAPF (Le Maître et al. 1989), correspondendo aos granitos s.s. $(3 \mathrm{a}=$ sienogranitos; $3 b=$ monzogranitos) (Pinto-Coelho 1996).

A fácies (g1a) encontra-se fortemente deforma$\mathrm{da}$, com foliação mergulhando para $\mathrm{W}$, e aflora na porção ocidental do maciço. A mineralogia essencial está constituída por quartzo, biotita, mica branca, feldspato potássico e albita. Feldspato potássico (microclínio) apresenta-se em três gerações de cristalização distintas: (i) fenocristais com tendência subautomórfica, com blastese nas bordas e presença acentuada de inclusões fluidas, (ii) cristais subautomórficos a xenomórficos, comumente intersticiais, e com acentuado aspecto turvo, e (iii) uma terceira geração representada por indivíduos límpidos, desprovidos de quaisquer inclusões e restritos à matriz da rocha. O quartzo mostra-se, sobretudo, em agregados policristalinos matriciais fortemente recristalizados. Plagioclásio (albita) apresenta, igualmente ao feldspato potássico, três gerações de cristalização: cristais subautomórficos a xenomórficos, pouco alongados, com maclas polissintéticas simples pouco deformadas, por vezes em fenocristais; contém, freqüentemente, abundantes inclusões de mica branca, fluorita, biotita e minerais argilosos. Não foi observado qualquer zoneamento químico entre as bordas e os núcleos destes minerais, cujas composições variam sistematicamente entre $\mathrm{Ab}_{93}$ e $\mathrm{Ab}_{98}$ (dados obtidos em microssonda eletrônica por Pinto-Coelho 1996). A segunda geração de albita constitui-se de indivíduos menores, igualmente subautomórficos a xenomórficos, geralmente límpidos e com poucas inclusões sólidas; sua composição química assemelha-se à dos plagioclásios de primeira geração. Observa-se, por vezes, textura do tipo mirmequita. $\mathrm{O}$ terceiro tipo de plagioclásio é constituído pela geração de albita sob forma de exsoluções em feldspato potássico de primeira geração.

A fácies $(\mathrm{g} 1 \mathrm{~b})$ possui características petrográficas semelhantes às da (g1a), exceto no que se refere ao aumento da deformação em (g1b) e, igualmente, às maiores proporções modais de quartzo, mica branca, fluorita, microclínio tardio e de fases minerais acessórias radioativas e a ETR, denotando, assim, maior desenvolvimento de processos de alteração pós-magmáticos (Pinto-Coelho et al. 1999). Encontram-se, nesta fácies, cristais reliquiares de almandina e de plagioclásio de composição mais cálcica $\left(\mathrm{An}_{20-23}\right)$.

A fácies ( $\mathrm{g} 1 \mathrm{c})$, a mais diferenciada do MGSB, aflora na porção oriental. Tem mineralogia composta por quartzo, albita, microclínio pertítico e mica branca, com as proporções modais desta última sendo nitidamente superiores às das demais fácies.

$\mathrm{Na}$ porção oriental aflora a fácies $(\mathrm{g} 1 \mathrm{~d})$ com características petrográficas semelhantes à fácies $(\mathrm{g} 1 \mathrm{c})$, contendo topázio em proporções modais em torno de $4 \%$. Os minerais acessórios, em porcentagens modais inferiores a $1 \%$, são zircão, topázio, monazita e apatita; minerais secundários são allanita, fluorita, óxidos/ hidróxidos de ferro e opacos. Contato tectônico é observado entre as fácies (g1a) e (g1c); os contatos entre as demais fácies não foram observados no campo.

Filões micáceos orientados NS a N15-30W associam-se, preferencialmente, à fácies (g1c) e aos greisens. Compõem-se de $95 \%$ de micas com granulação fina à muita fina e cor esverdeada característica. Os minerais acessórios são topázio, zircão e apatita; minerais secundários são quartzo, opacos e, mais raramente, epidoto e fenacita. Estes filões, assim como os greisens, são afetados por foliação levemente inclinada para E.

Importantes variações observadas na composição modal dos granitos do MGSB resultam da atuação de processos pós-magmáticos: albitização, greisenização (a mais desenvolvida) e microclinização. A greisenização modifica inteiramente a textura da rocha original e é responsável pela formação de greisens maciços observados na porção oriental do MGSB. A composição mineralógica dos greisens é dominada pela associação quartzo-mica branca; topázio, fluorita, cassiterita, berilo, monazita, scheelita, grafita, esfalerita, zoisita, zircão, apatita, fenacita e opacos (sobretudo minerais de $\mathrm{Cu}$ e $\mathrm{Fe}$ ) são acessórios freqüentes. Nos greisens da porção oriental são reconhecidas várias gerações de cada uma dessas fases minerais, evidenciando, assim, a importância da recristalização que modifica a textura da rocha inicial. O quartzo, disposto intersticialmente ou em agregados policristalinos, mostra deformação moderada, denotando a amplitude da recristalização. Fraturas são habitualmente preenchidas por mica branca ( \pm clorita).

Feldspatos da rocha original são raramente conservados nos greisens, sob forma de relictos de albita, comumente inclusos em quartzo e cuja composição é idêntica à do plagioclásio do granito $(\mathrm{g} 1 \mathrm{c})$ (Pinto-Coelho 1996). O feldspato potássico neoformado é abundante: microclínio não pertítico, com geminação em grade bem desenvolvida, em indivíduos xenomórficos límpidos é visivelmente posterior à deformação geral, apresentando, localmente, xistosidade interna desenhada por lamelas de grafita. Com cristalização tardia, esse mineral apresenta composição comparável àquela do microclínio de terceira geração identificado nas demais fácies graníticas do MGSB. O processo de microclinização é, assim, um fenômeno de alteração pós-greisen, desenvolvido de maneira intensa, levando, por vezes, à formação de bolsões monominerálicos.

Os granitos do MGSB são silicosos $\left(\mathrm{SiO}_{2}=73\right.$ - 76\%), potássicos $\left(\mathrm{K}_{2} \mathrm{O}=4-5 \%\right)$, fraca a moderadamente sódicos $\left(\mathrm{Na}_{2} \mathrm{O}=2-3,5 \%\right)$, pouco ferríferos $\left(\mathrm{Fe}_{2} \mathrm{O}_{3}=0,67-1,5 \%\right)$, praticamente desprovidos de óxidos de $\mathrm{Ca}, \mathrm{Mg}$ e Ti e pobres em F $(0,12-0,91 \%)$ e Li (16 - 100 ppm). As alterações pós-magmáticas modificaram a assinatura geoquímica original destas rochas, de maneira que as variações de composição químicomineralógicas observadas entre as diferentes fácies resultam destas modificações, preferencialmente a processos magmáticos (Pinto-Coelho 1996; Pinto-Coelho 
et al. 1999).

QUÍMICA MINERAL As fases micáceas do MGSB foram analisadas em microssonda eletrônica Camebax SX - 50, na Universidade de Nancy I - França, com as seguintes condições analíticas: alta tensão a $15 \mathrm{kV}$, corrente a $10 \mathrm{nA}$, tempo de contagem sobre os picos de 10 segundos e de 5 segundos sobre o background. As fórmulas estruturais foram calculadas com base em
22 oxigênios ( $\mathrm{Fe}$ como $\mathrm{FeO}_{\mathrm{t}}$ ), conforme recomendado em Deer et al. (2000). Os resultados analíticos de biotita são mostrados na tabela 1 e os de micas brancas na tabela 2 .

Análises químicas por via úmida foram realizadas no Laboratório de Análises Químicas do Centre de Recherches Pétrographiques et Géochimiques, em Vandoeuvre-lès-Nancy, França, por meio de ICP-MS, em fusão com $\mathrm{LiBO}_{2}$ e dissolução por $\mathrm{HNO}_{3}$.

Tabela 1 - Média das análises químicas por microssonda eletrônica de biotita das fácies graníticas (gla), ( $\mathrm{glb}$ e e (glc) do Maciço da Serra Branca. $\mathrm{n}=$ número de análises; $\mathrm{x}=$ média aritmética; $\mathrm{m}$ = mediana $; \sigma=$ desvio padrão.

\begin{tabular}{|c|c|c|c|c|c|c|c|c|c|}
\hline & \multicolumn{3}{|c|}{$\mathrm{g} 1 \mathrm{a}(\mathrm{n}=23)$} & \multicolumn{3}{|c|}{$\mathrm{g} 1 \mathrm{~b}(\mathrm{n}=17)$} & \multicolumn{3}{|c|}{$\mathrm{g} 1 \mathrm{c}(\mathrm{n}=18)$} \\
\hline & $\mathrm{x}$ & $\mathrm{m}$ & $\sigma$ & $\mathrm{x}$ & $\mathrm{m}$ & $\sigma$ & $\mathrm{x}$ & $\mathrm{m}$ & $\sigma$ \\
\hline $\mathrm{SiO} 2$ & 33,81 & 33,80 & 0,44 & 34,80 & 34,49 & 1,01 & 33,51 & 33,54 & 0,47 \\
\hline $\mathrm{A} 12 \mathrm{O} 3$ & 16,74 & 16,69 & 0,23 & 16,61 & 16,58 & 0,72 & 17,16 & 16,95 & 0,94 \\
\hline $\mathrm{TiO} 2$ & 2,15 & 2,07 & 0,51 & 1,48 & 1,62 & 0,39 & 1,46 & 1,36 & 0,45 \\
\hline $\mathrm{FeO}$ & 31,84 & 32,28 & 1,36 & 27,62 & 26,96 & 1,94 & 33,19 & 33,50 & 1,31 \\
\hline $\mathrm{MnO}$ & 0,13 & 0,12 & 0,08 & 0,18 & 0,15 & 0,09 & 0,22 & 0,19 & 0,12 \\
\hline $\mathrm{MgO}$ & 1,05 & 1,19 & 0,80 & 4,04 & 4,84 & 1,38 & 0,29 & 0,29 & 0,06 \\
\hline $\mathrm{CaO}$ & 0,00 & 0,00 & 0,00 & 0,00 & 0,00 & 0,01 & 0,00 & 0,00 & 0,01 \\
\hline $\mathrm{Cr} 2 \mathrm{O} 3$ & 0,00 & 0,00 & 0,01 & 0,01 & 0,00 & 0,02 & 0,01 & 0,00 & 0,02 \\
\hline $\mathrm{NiO}$ & 0,02 & 0,00 & 0,04 & 0,02 & 0,00 & 0,03 & 0,02 & 0,00 & 0,05 \\
\hline $\mathrm{Na} 2 \mathrm{O}$ & 0,05 & 0,06 & 0,04 & 0,06 & 0,06 & 0,03 & 0,04 & 0,03 & 0,04 \\
\hline $\mathrm{K} 2 \mathrm{O}$ & 9,25 & 9,30 & 0,22 & 9,39 & 9,42 & 0,28 & 9,23 & 9,20 & 0,19 \\
\hline $\mathrm{F}$ & 0,61 & 0,70 & 0,26 & 1,11 & 1,34 & 0,48 & 1,26 & 1,34 & 0,56 \\
\hline $\mathrm{Rb} 2 \mathrm{O}$ & 0,11 & 0,12 & 0,06 & 0,09 & 0,08 & 0,07 & 0,15 & 0,16 & 0,08 \\
\hline TOTAL & 95,78 & 95,89 & 1,31 & 95,41 & 95,31 & 1,07 & 96,38 & 96,47 & 1,25 \\
\hline $\mathrm{Si}$ & 5,52 & 5,53 & 0,05 & 5,61 & 5,60 & 0,08 & 5,51 & 5,51 & 0,04 \\
\hline Al IV & 2,61 & 2,47 & 0,62 & 2,39 & 2,40 & 0,08 & 2,49 & 2,49 & 0,04 \\
\hline Al VI & 0,74 & 0,77 & 0,09 & 0,76 & 0,74 & 0,11 & 0,84 & 0,80 & 0,17 \\
\hline $\mathrm{Fe}$ & 4,37 & 4,43 & 0,23 & 3,73 & 3,65 & 0,30 & 4,54 & 4,58 & 0,19 \\
\hline $\mathrm{Mg}$ & 0,25 & 0,29 & 0,19 & 0,97 & 1,17 & 0,32 & 0,07 & 0,07 & 0,02 \\
\hline $\mathrm{Mn}$ & 0,02 & 0,02 & 0,01 & 0,03 & 0,02 & 0,01 & 0,03 & 0,03 & 0,02 \\
\hline Ti & 0,26 & 0,26 & 0,06 & 0,18 & 0,20 & 0,05 & 0,18 & 0,17 & 0,05 \\
\hline $\mathrm{Y}$ & 5,63 & 5,64 & 0,03 & 5,66 & 5,67 & 0,04 & 5,67 & 5,68 & 0,07 \\
\hline $\mathrm{Ca}$ & 0,00 & 0,00 & 0,00 & 0,00 & 0,00 & 0,00 & 0,00 & 0,00 & 0,00 \\
\hline $\mathrm{Na}$ & 0,03 & 0,02 & 0,04 & 0,02 & 0,02 & 0,01 & 0,01 & 0,01 & 0,01 \\
\hline $\mathrm{K}$ & 1,92 & 1,93 & 0,07 & 1,93 & 1,92 & 0,06 & 1,94 & 1,93 & 0,03 \\
\hline$X$ & 1,93 & 1,94 & 0,08 & 1,95 & 1,95 & 0,06 & 1,95 & 1,94 & 0,03 \\
\hline XYZ & 15,58 & 15,59 & 0,04 & 15,61 & 15,62 & 0,07 & 15,62 & 15,63 & 0,06 \\
\hline $\mathrm{XFe}$ & 0,95 & 0,94 & 0,04 & 0,75 & 0,76 & 0,18 & 0,99 & 0,99 & 0,00 \\
\hline
\end{tabular}


Mica tri-octaédrica: biotita Os minerais ferromagnesianos são bons indicadores das condições físicoquímicas vigentes durante sua cristalização. A biotita, e os filossilicatos em geral, em virtude das diversas possibilidades de substituição nas camadas tetraédricas, octaédricas ou em posição interfoliar, testemunham, particularmente, sobre condições de $\mathrm{P}, \mathrm{T}, \mathrm{aH}_{2} \mathrm{O}, \mathrm{aF}$, $\mathrm{fO}_{2}$ e composição do magma - $\mathrm{Al}, \mathrm{Fe}, \mathrm{Mg}, \mathrm{Li}$ e $\mathrm{Rb}$. Entretanto, esse mineral revela-se bastante sensível a variações das condições externas, reequilibrando-se facilmente e mesmo que se mostre petrograficamente sã, pode apresentar composição que não reflete as condições magmáticas estritamente originais presentes no momento de sua cristalização.

A biotita é a única fase mineral ferromagnesiana presente no MGSB, contrariamente ao que se observa em outros maciços da Província Estanífera de Goiás, onde o anfibólio pode ser encontrado (e.g. granito Serra da Mesa, Bilal 1991). Na fácies (g1a), esta mica apresenta-se em agregados contendo lamelas geralmente alongadas, automorfas a subautomorfas, com cor verde a esverdeada ou, ainda, em placas isoladas na matriz da rocha (Fig. 2a). Apresenta-se comumente cloritizada e/ou muscovitizada, com óxidos de $\mathrm{Fe}$ e Ti dispostos ao longo das clivagens. Esta mica não é encontrada no granito (g1c), à exceção de diminutos cristais subautomorfos inclusos em quartzo (Fig. 2b).

A biotita mostra-se geralmente homogênea ao longo do cristal (inexistência de zoneamento núcleo borda) ou da amostra. Contrariamente, os teores de Fe, $\mathrm{Mg}, \mathrm{Al}$ e Ti são variáveis entre as diferentes amostras de uma mesma fácies petrográfica, onde a heterogeneidade poderia corresponder tanto a diferentes estágios da diferenciação magmática, quanto a um reequilíbrio relacionado à alteração intensa que exagerou ou mascarou as diferenças primárias entre os cristais de biotita das distintas fácies petrográficas. A biotita do MGSB não apresenta grandes disparidades químicas, projetando-se no domínio da composição da biotita associada à muscovita no diagrama triangular proposto por No- ckolds (1947).

Todas as análises de biotita do MGSB comportam Al em posição octaédrica, sendo, assim, aluminosas. As lacunas octaédricas são a regra: confrontar, na tabela 1, a diferença entre XYZ e o valor de 16 cátions para biotita teórica: $\mathrm{Si}_{6} \mathrm{Al}_{2}(\mathrm{Fe}, \mathrm{Mg})_{6} \mathrm{~K}_{2} \mathrm{O}_{20}(\mathrm{OH})_{4}$. As análises sobre base de 22 oxigênios foram projetadas no diagrama retangular de Nachit et al. (1985), Al total versus $\mathrm{Mg}$, que estabelece a tipologia magmática das grandes suítes de granitóides (Fig. 3). Observa-se um agrupamento dos dados segundo um trend pouco inclinado com relação ao eixo $\mathrm{Mg}$, excetuando-se os termos mais ferríferos (fácies g1c), distribuídos paralelamente ao eixo $\mathrm{Al}$ total, nos domínios dos granitos cálcio-alcalinos a subalcalinos.

A figura 4 mostra a variação de $\mathrm{Al}^{\mathrm{IV}}$ e $\mathrm{Al}^{\mathrm{VI}} \mathrm{em}$ relação a $\mathrm{XFe}$. $\mathrm{Al}^{\mathrm{IV}}$ é sempre excedente, variando entre 2,20 e 2,40 a.f.u. sobre 22 oxigênios. $\mathrm{Al}^{\mathrm{VI}}$ mostra a maior variação interna, onde a biotita mais ferrrífera (fácies g1c) tem um componente muscovita não negligenciável.

A figura 5 mostra a variação dos teores de $\mathrm{F}$ em relação a XFe (fórmula estrutural). Observa-se um trend negativo, exceção feita à biotita inclusa em quartzo da fácies $(\mathrm{g} 1 \mathrm{c})$, para a qual $\mathrm{F}$ varia com XFe constante.

Mica di-octaédrica: mica branca As rochas graníticas do MGSB contêm mica branca em quantidade e hábitos variáveis. Os greisens apresentam apenas mica branca em sua composição mineralógica essencial. Esta mica está presente, ainda, nas encaixantes diretas do maciço (quartzitos do Grupo Araí).

As micas brancas, independente da rocha hospedeira (granitos, greisens, filões micáceos ou quartzitos encaixantes), apresentam grande variedade de hábitos: a) numerosas inclusões não orientadas em plagioclásios dos granitos, o que contrasta com a quase total ausência em feldspatos alcalinos, primários ou tardios (Fig. 6a); b) no preenchimento de fraturas, fre-
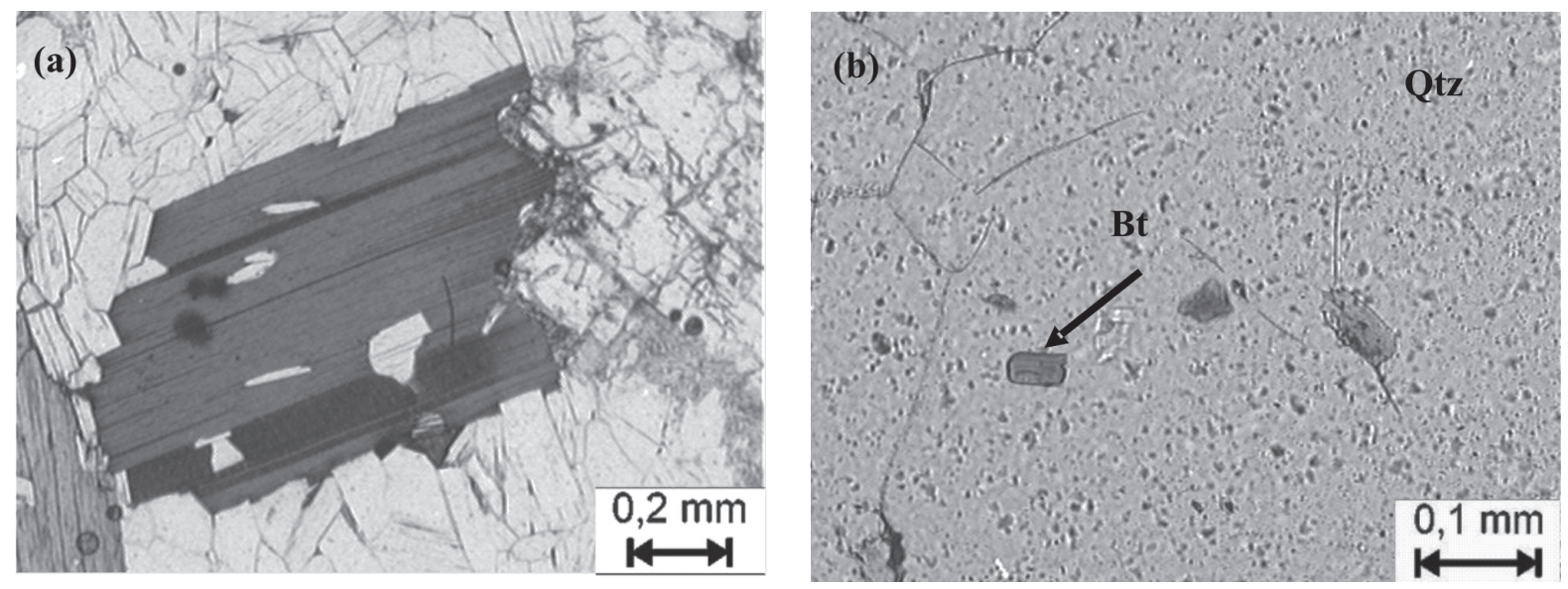

Figura 2 - Fotomicrografias em nicóis paralelos: a) lamelas alongadas de biotita, automorfas a subautomorfas, com óxidos de Fe ao longo das clivagens. Fácies (gla); b) diminutos cristais de biotita subautomorfos inclusos em quartzo em granito da fácies (glc). Bt = biotita; Qtz = quartzo. 
Tabela 2 - Média das análises químicas por microssonda eletrônica de micas brancas das fácies graníticas, de greisens, de filóes micáceos e das encaixantes do Maciço da Serra Branca. $\mathrm{n}$ = número de análises; $\mathrm{x}=$ média aritmética; $\mathrm{m}=$ mediana; $\sigma=$ desvio padrão. Para a descrição das fácies graníticas, ver texto.

\begin{tabular}{|c|c|c|c|c|c|c|c|c|c|c|c|c|}
\hline & \multicolumn{3}{|c|}{ g1a $(n=31)$} & \multicolumn{3}{|c|}{$\mathrm{g} 1 \mathrm{~b}(\mathrm{n}=7)$} & \multicolumn{3}{|c|}{$\mathrm{g} 1 \mathrm{c}(\mathrm{n}=58)$} & \multicolumn{3}{|c|}{$\operatorname{g1d}(\mathrm{n}=27)$} \\
\hline & $\mathrm{x}$ & $\mathrm{m}$ & $\sigma$ & $\mathrm{x}$ & $\mathrm{m}$ & $\sigma$ & $\mathrm{x}$ & $\mathrm{m}$ & $\sigma$ & $\mathrm{x}$ & $\mathrm{m}$ & $\sigma$ \\
\hline $\mathrm{SiO} 2$ & 48,34 & 48,46 & 0,67 & 48,91 & 48,59 & 1,38 & 48,05 & 47,84 & 1,31 & 49,01 & 49,08 & 1,08 \\
\hline $\mathrm{A} 12 \mathrm{O} 3$ & 30,46 & 30,76 & 1,23 & 29,79 & 29,99 & 0,63 & 29,71 & 29,19 & 2,27 & 29,16 & 29,41 & 1,52 \\
\hline $\mathrm{TiO} 2$ & 0,19 & 0,20 & 0,11 & 0,18 & 0,19 & 0,16 & 0,10 & 0,08 & 0,09 & 0,06 & 0,04 & 0,06 \\
\hline $\mathrm{FeO}$ & 4,83 & 4,61 & 0,94 & 4,23 & 3,93 & 0,62 & 6,01 & 6,37 & 1,85 & 6,29 & 6,20 & 1,20 \\
\hline $\mathrm{MnO}$ & 0,04 & 0,02 & 0,05 & 0,06 & 0,02 & 0,07 & 0,07 & 0,06 & 0,06 & 0,10 & 0,09 & 0,08 \\
\hline $\mathrm{MgO}$ & 0,68 & 0,75 & 0,32 & 1,35 & 1,42 & 0,26 & 0,19 & 0,11 & 0,16 & 0,06 & 0,06 & 0,04 \\
\hline $\mathrm{CaO}$ & 0,01 & 0,00 & 0,03 & 0,01 & 0,00 & 0,02 & 0,00 & 0,00 & 0,02 & 0,01 & 0,00 & 0,02 \\
\hline $\mathrm{Cr} 2 \mathrm{O} 3$ & 0,03 & 0,00 & 0,11 & 0,00 & 0,00 & 0,00 & 0,01 & 0,00 & 0,02 & 0,01 & 0,00 & 0,01 \\
\hline $\mathrm{NiO}$ & 0,03 & 0,00 & 0,04 & 0,04 & 0,05 & 0,03 & 0,02 & 0,00 & 0,04 & 0,02 & 0,00 & 0,03 \\
\hline $\mathrm{Na} 2 \mathrm{O}$ & 0,19 & 0,20 & 0,05 & 0,30 & 0,21 & 0,25 & 0,27 & 0,23 & 0,29 & 0,19 & 0,18 & 0,05 \\
\hline $\mathrm{K} 2 \mathrm{O}$ & 10,60 & 10,74 & 0,49 & 10,03 & 10,71 & 0,99 & 10,70 & 10,75 & 0,38 & 10,26 & 10,78 & 1,26 \\
\hline $\mathrm{F}$ & 0,35 & 0,31 & 0,22 & 0,53 & 0,56 & 0,16 & 1,41 & 1,19 & 0,97 & 2,68 & 2,63 & 0,51 \\
\hline $\mathrm{Rb} 2 \mathrm{O}$ & 0,04 & 0,04 & 0,04 & 0,03 & 0,01 & 0,04 & 0,08 & 0,08 & 0,04 & 0,14 & 0,09 & 0,13 \\
\hline TOTAL & 95,78 & 95,73 & 1,42 & 95,46 & 95,43 & 1,18 & 96,60 & 96,57 & 1,65 & 97,93 & 98,56 & 1,83 \\
\hline $\mathrm{Si}$ & 6,51 & 6,50 & 0,13 & 6,60 & 6,58 & 0,12 & 6,56 & 6,54 & 0,16 & 6,66 & 6,66 & 0,11 \\
\hline Al IV & 1,49 & 1,50 & 0,13 & 1,40 & 1,42 & 0,12 & 1,44 & 1,47 & 0,16 & 1,34 & 1,34 & 0,11 \\
\hline Al VI & 3,35 & 3,38 & 0,19 & 3,34 & 3,35 & 0,06 & 3,33 & 3,31 & 0,18 & 3,33 & 3,31 & 0,16 \\
\hline $\mathrm{Fe}$ & 0,54 & 0,51 & 0,10 & 0,48 & 0,44 & 0,08 & 0,69 & 0,74 & 0,22 & 0,72 & 0,71 & 0,14 \\
\hline $\mathrm{Mg}$ & 0,14 & 0,15 & 0,07 & 0,27 & 0,28 & 0,05 & 0,04 & 0,02 & 0,03 & 0,01 & 0,01 & 0,01 \\
\hline $\mathrm{Mn}$ & 0,00 & 0,00 & 0,01 & 0,01 & 0,00 & 0,01 & 0,01 & 0,01 & 0,01 & 0,01 & 0,01 & 0,01 \\
\hline $\mathrm{Ti}$ & 0,02 & 0,02 & 0,01 & 0,02 & 0,02 & 0,02 & 0,01 & 0,01 & 0,01 & 0,01 & 0,00 & 0,01 \\
\hline Y & 4,05 & 4,08 & 0,18 & 4,11 & 4,09 & 0,07 & 4,08 & 4,09 & 0,06 & 4,08 & 4,05 & 0,06 \\
\hline $\mathrm{Na}$ & 0,17 & 0,05 & 0,66 & 0,08 & 0,05 & 0,06 & 0,07 & 0,06 & 0,07 & 0,05 & 0,05 & 0,01 \\
\hline K & 1,82 & 1,84 & 0,10 & 1,73 & 1,82 & 0,17 & 1,86 & 1,87 & 0,07 & 1,78 & 1,86 & 0,22 \\
\hline $\mathrm{X}$ & 1,99 & 1,90 & 0,63 & 1,80 & 1,87 & 0,13 & 1,93 & 1,93 & 0,05 & 1,83 & 1,92 & 0,22 \\
\hline XYZ & 14,05 & 13,97 & 0,45 & 13,92 & 13,97 & 0,11 & 14,01 & 14,01 & 0,05 & 13,91 & 13,98 & 0,17 \\
\hline $\mathrm{XFe}$ & 0,80 & 0,76 & 0,09 & 0,64 & 0,61 & 0,06 & 0,94 & 0,98 & 0,06 & 0,98 & 0,98 & 0,01 \\
\hline
\end{tabular}

qüentemente regulares em fenocristais de K-feldspato nas fácies (gla) e (g1b), o que poderia corresponder a fraturas de retração térmica (Wilhelm 1977) (Fig. 6b); c) agregados de cristais subédricos associados ou intercrescidos com biotita, tendo comumente minerais ferruginosos ao longo de clivagens (Fig. 6c); d) as relações com o topázio dão-se de maneira distintas, seja sob forma de inclusões, preenchimento de fraturas ou substituição (Fig. 6d); e) dispostas intersticialmente em todas as fácies petrográficas sob forma de lamelas em matriz quartzo-feldspática (Fig. 6e); f) nos quartzitos encaixantes, as micas brancas ocorrem em finas placas intersticiais ou cristais maiores marcando a xistosidade (Fig. 6f); g) nos greisens, constituem a mineralogia essencial. E igualmente heterogênea e apresenta-se em diversas gerações de cristalização: em placas com dimensões medianas, por vezes deformadas e marcando uma xistosidade grosseira ou em forma de agregados de diminutas palhetas imersas na mesóstase. Freqüente, ainda, sob forma de inclusões em topázio e fluorita; a cassiterita, quando presente, encontra-se fraturada, onde uma segunda geração de mica branca, orientada e 


\begin{tabular}{|c|c|c|c|c|c|c|c|c|c|}
\hline & \multicolumn{3}{|c|}{ greisens $(\mathrm{n}=93)$} & \multicolumn{3}{|c|}{ filões ( $\mathrm{n}=15)$} & \multicolumn{3}{|c|}{ encaixante $(n=24)$} \\
\hline & $\mathrm{x}$ & $\mathrm{m}$ & $\sigma$ & $\mathrm{x}$ & $\mathrm{m}$ & $\sigma$ & $\mathrm{x}$ & $\mathrm{m}$ & $\sigma$ \\
\hline $\mathrm{SiO} 2$ & 47,99 & 48,00 & 0,99 & 47,86 & 47,70 & 0,82 & 48,98 & 49,06 & 1,60 \\
\hline $\mathrm{A} 12 \mathrm{O} 3$ & 31,62 & 32,06 & 1,81 & 33,97 & 33,42 & 1,29 & 31,72 & 31,72 & 1,00 \\
\hline $\mathrm{TiO} 2$ & 0,05 & 0,00 & 0,10 & 0,03 & 0,02 & 0,03 & 0,31 & 0,34 & 0,19 \\
\hline $\mathrm{FeO}$ & 4,16 & 3,77 & 1,88 & 2,67 & 3,12 & 0,87 & 3,54 & 3,33 & 1,47 \\
\hline $\mathrm{MnO}$ & 0,06 & 0,06 & 0,06 & 0,08 & 0,09 & 0,06 & 0,02 & 0,00 & 0,04 \\
\hline $\mathrm{MgO}$ & 0,44 & 0,42 & 0,23 & 0,29 & 0,31 & 0,05 & 1,44 & 1,33 & 0,31 \\
\hline $\mathrm{CaO}$ & 0,01 & 0,00 & 0,03 & 0,01 & 0,00 & 0,01 & 0,00 & 0,00 & 0,01 \\
\hline $\mathrm{Cr} 2 \mathrm{O} 3$ & 0,01 & 0,00 & 0,02 & 0,00 & 0,00 & 0,01 & 0,01 & 0,00 & 0,03 \\
\hline $\mathrm{NiO}$ & 0,03 & 0,00 & 0,05 & 0,03 & 0,00 & 0,04 & 0,03 & 0,00 & 0,05 \\
\hline $\mathrm{Na} 2 \mathrm{O}$ & 0,25 & 0,24 & 0,10 & 0,29 & 0,30 & 0,05 & 0,30 & 0,23 & 0,15 \\
\hline $\mathrm{K} 2 \mathrm{O}$ & 10,33 & 10,79 & 1,10 & 10,70 & 10,72 & 0,26 & 10,42 & 10,64 & 0,69 \\
\hline $\mathrm{F}$ & 0,95 & 0,82 & 0,82 & 0,68 & 0,91 & 0,39 & 0,26 & 0,00 & 0,35 \\
\hline $\mathrm{Rb} 2 \mathrm{O}$ & 0,11 & 0,10 & 0,12 & 0,06 & 0,05 & 0,04 & 0,03 & 0,02 & 0,04 \\
\hline TOTAL & 96,00 & 96,06 & 1,70 & 96,41 & 96,99 & 1,56 & 97,07 & 97,22 & 2,28 \\
\hline $\mathrm{Si}$ & 6,48 & 6,49 & 0,10 & 6,36 & 6,38 & 0,08 & 6,47 & 6,49 & 0,09 \\
\hline Al IV & 1,52 & 1,51 & 0,10 & 1,64 & 1,62 & 0,08 & 1,53 & 1,51 & 0,09 \\
\hline $\mathrm{Al}$ VI & 3,50 & 3,53 & 0,17 & 3,67 & 3,62 & 0,09 & 3,41 & 3,40 & 0,12 \\
\hline $\mathrm{Fe}$ & 0,47 & 0,42 & 0,22 & 0,30 & 0,34 & 0,10 & 0,39 & 0,37 & 0,16 \\
\hline $\mathrm{Mg}$ & 0,10 & 0,08 & 0,11 & 0,06 & 0,06 & 0,01 & 0,28 & 0,26 & 0,06 \\
\hline $\mathrm{Mn}$ & 0,01 & 0,01 & 0,01 & 0,01 & 0,01 & 0,01 & 0,00 & 0,00 & 0,00 \\
\hline $\mathrm{Ti}$ & 0,00 & 0,00 & 0,01 & 0,00 & 0,00 & 0,00 & 0,03 & 0,04 & 0,02 \\
\hline Y & 4,08 & 4,05 & 0,08 & 4,04 & 4,04 & 0,02 & 4,11 & 4,08 & 0,08 \\
\hline $\mathrm{Na}$ & 0,07 & 0,06 & 0,03 & 0,08 & 0,08 & 0,01 & 0,08 & 0,06 & 0,04 \\
\hline K & 1,78 & 1,86 & 0,19 & 1,81 & 1,82 & 0,03 & 1,76 & 1,81 & 0,14 \\
\hline $\mathrm{X}$ & 1,85 & 1,93 & 0,20 & 1,89 & 1,90 & 0,04 & 1,84 & 1,90 & 0,15 \\
\hline $\mathrm{XYZ}$ & 13,93 & 13,97 & 0,15 & 13,93 & 13,94 & 0,03 & 13,95 & 13,98 & 0,08 \\
\hline $\mathrm{XFe}$ & 0,83 & 0,83 & 0,09 & 0,82 & 0,85 & 0,05 & 0,56 & 0,60 & 0,10 \\
\hline
\end{tabular}

com textura crack seal, solda os diferentes fragmentos (Fig. 6g); h) filões micáceos constituem-se de $95 \%$ de mica branca, seja marcando a xistosidade, seja secante à mesma, ou ainda encontra-se sob forma de inclusões em fenocristais de berilo (Fig. 6h).

As composições das diversas gerações de mica branca nas rochas do MGSB são mostradas na tabela 2. Devido ao elevado número de dados e ao fato de não haver variações químicas sistemáticas em relação às distintas formas de ocorrência anteriormente mencionadas e mostradas na figura 6 , nem ocorrer variação no interior de um mesmo cristal (zoneamento núcleo/ borda), os resultados obtidos em microssonda eletrônica estão agrupados na tabela por tipo de rocha, com as respectivas médias, medianas e desvio padrão de cada grupo.

Quatro tipos ou grupos petrográficos foram estabelecidos com base em dados analíticos, independentemente de hábito, localização ou cronologia aparente: a) micas brancas das fácies (g1a, g1b e g1c); b) micas brancas da fácies (g1d); c) micas brancas dos greisens e filões micáceos; d) micas brancas das rochas encai- 


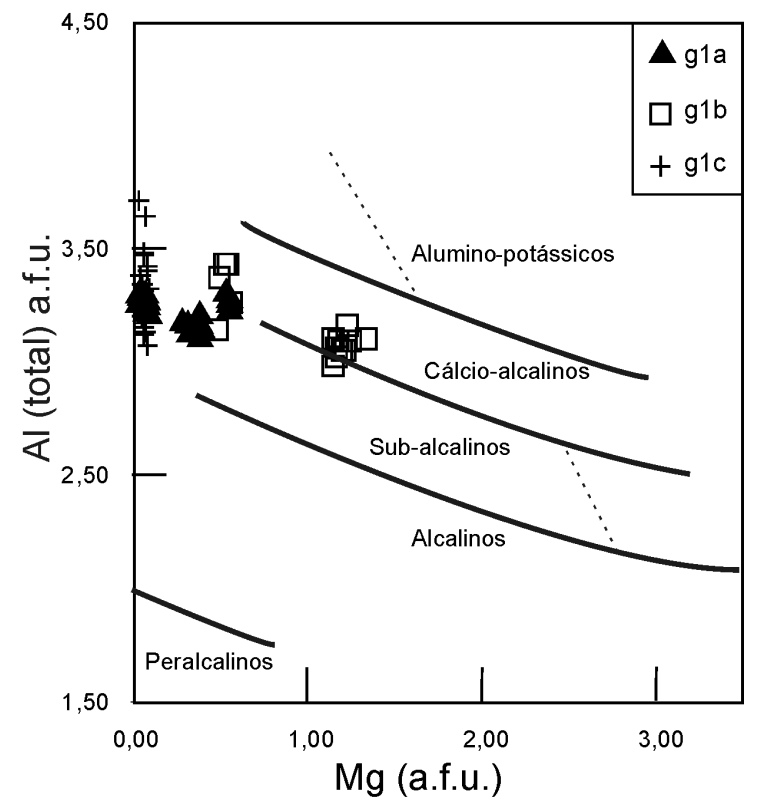

Figura 3 - Diagrama Al total versus Mg (Nachit et al. 1985) para biotita do MGSB.
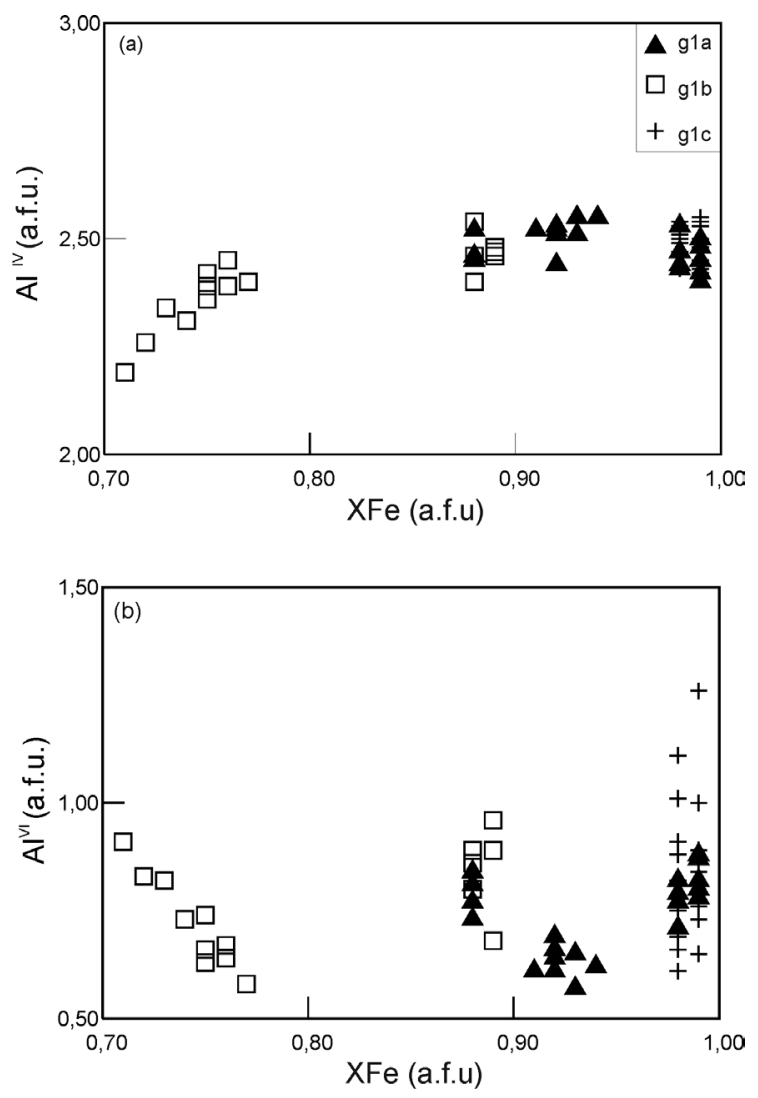

Figura 4 - Diagrama (a) $A l^{I V}$ e (b) $A l^{V I}$ versus $X F$ e para biotita do $M G S B$.

xantes. As variações geoquímicas não são importantes e, assim como para a biotita, são mais marcantes no interior de um mesmo grupo do que entre as diferentes fácies observadas. As micas brancas são ferríferas,

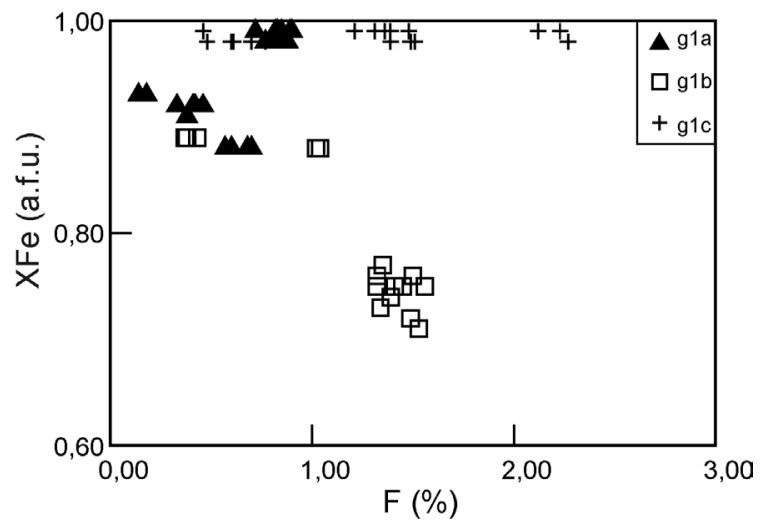

Figura 5 - Razão XFe versus F para biotita do $M G S B$.

fracamente magnesianas e titaníferas, medianamente fluoretadas $(0,3$ a $2,7 \%$ em peso $)$ e não litiníferas (Pinto-Coelho 1996).

Do ponto de vista geoquímico, os termos extremos da série muscovita são, de acordo com Monier (1985): (a) muscovita s.s. $\mathrm{K}\left(\mathrm{Al}_{2} \square\right)\left(\mathrm{Si}_{3}, \mathrm{Al}\right) \mathrm{O}_{10}(\mathrm{OH}, \mathrm{F})_{2}$; (b) celadonita $\mathrm{K}\left(\mathrm{Al}, \mathrm{M}^{2+}, \square\right) \mathrm{Si}_{4} \mathrm{O}_{10}(\mathrm{OH}, \mathrm{F})_{2}$, os termos intermediários definidos como fengitas; (c) paragonita, com $\mathrm{K} \rightarrow \mathrm{Na}$; a paragonita é uma fase geralmente discreta, exceção feita a contextos metamórficos de alta pressão (Guidotti 1978).

Micas brancas não litiníferas são descritas geralmente como soluções sólidas entre o membro final muscovita $\mathrm{K}\left(\mathrm{Al}_{2} \square\right)\left(\mathrm{Si}_{3} \mathrm{Al}\right) \mathrm{O}_{10}(\mathrm{OH})_{2}$, onde $\square$ é o sítio octaédrico vacante, e o membro celadonita $\mathrm{K}\left(\mathrm{Al}, \mathrm{M}^{2}+\square\right)$ $\mathrm{Si}_{4} \mathrm{O}_{10}(\mathrm{OH})_{2}$, com $\mathrm{M}^{2+}=\mathrm{Mg}^{2+}, \mathrm{Fe}^{2+}$, consideradas como pertencentes à série fengítica (Monier \& Robert 1986a).

A substituição fengítica é a mais importante e a grande maioria das micas brancas são fengitas s.l. Tal substituição, também conhecida como substituição celadonítica ou Al-Tschermak, pode ser definida pela equação (1):

$$
\begin{aligned}
& \mathrm{Al}^{\mathrm{VI}}+\mathrm{Al}^{\mathrm{IV}} \Rightarrow \mathrm{Si}^{\mathrm{IV}}+\left(\mathrm{M}^{2+}\right)^{\mathrm{VI}} \\
& \text { onde } \mathrm{M}^{2+}=\mathrm{Fe}^{2+}+\mathrm{Mg}+\mathrm{Mn}+\mathrm{Ti}
\end{aligned}
$$

havendo conservação do caráter dioctaédrico, mas modificando-se o conteúdo tetraédrico. Estudos experimentais mostram que a taxa de substituição $\mathrm{x}(0 \leq \mathrm{x} \leq$ 1) aumenta com a pressão da água e com a diminuição da temperatura (Miller et al. 1981).

A substituição biotítica ocasiona a perda do conteúdo dioctaédrico, mas, contrariamente, conserva o conteúdo tetraédrico, conforme equação (2):

$$
\begin{aligned}
& \left(2 / 3 \mathrm{Al}^{\mathrm{VI}}+1 / 3 \square\right)^{\mathrm{VI}} \Rightarrow\left(\mathrm{M}^{2+}\right)^{\mathrm{VI}} \mathrm{y} \\
& \text { (taxa de substituição) } \quad 0 \leq \mathrm{y} \leq 3
\end{aligned}
$$

As substituições x e y são, geralmente, encontradas em micas brancas naturais, cuja fórmula estrutural pode ser escrita de acordo com a equação (3): (Monier \& Robert 1986, 1986a): 

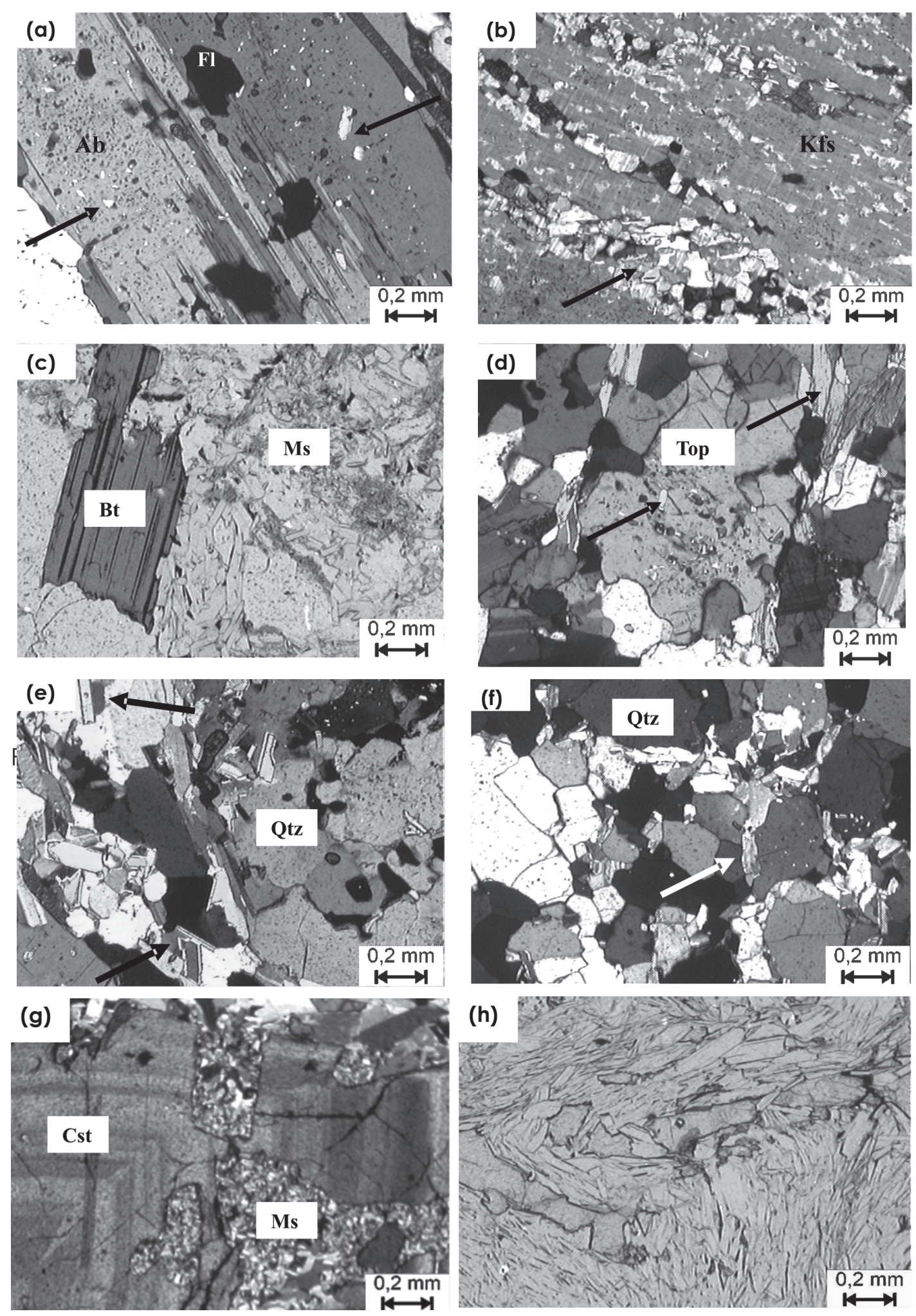

Figura 6 - Fotomicrografias das formas de ocorrência das micas brancas em granitos, greisens, filões micáceos e encaixantes do MGSB. (a) numerosas inclusões (setas) não orientadas em plagioclásios da fácies ( $\mathrm{gla}$ ); $N X ; \mathrm{Ab}=$ albita, $\mathrm{Fl}=$ fluorita; (b) no preenchimento de fraturas (seta) em fenocristais de K-feldspato (Kfs) na fácies ( $\mathrm{glb}$ ); NX; (c) agregados de cristais subédricos associados ou intercrescidos com biotita (fácies glb); N//; Bt = biotita; Ms = muscovita; (d) inclusões (setas) em topázio (Top) da fácies ( $\mathrm{gld}$ ); NX; (e) dispostas intersticialmente (setas) sob forma de lamelas em matriz quartzo-feldspática (fácies glc); NX; $Q t z=$ quartzo; (f) finas placas intersticiais (seta) ou cristais maiores marcando a xistosidade em quartzitos encaixantes; $N X$; (g) soldando fragmentos de cassiterita (Cst) nos greisens; $N X$; (h) como constituintes principais dos filóes micáceos; N//. 


$$
\mathrm{K}\left(\mathrm{Al}_{2-\mathrm{x}-\mathrm{2y} / 3} \mathrm{M}^{2+}{ }_{\mathrm{x}+\mathrm{y}} \square_{1-\mathrm{y} / 3}\right)^{\mathrm{VI}}\left(\mathrm{Si}_{3+\mathrm{x}} \mathrm{Al}_{1-\mathrm{x}}\right)^{\mathrm{IV}} \mathrm{O}_{10}(\mathrm{OH}, \mathrm{F})_{2}
$$

Outras substituições, envolvendo $\mathrm{Fe}^{3+}$ ou $\mathrm{Ti}^{4+}$ podem ser observadas (equações (4), (5) e (6):

$$
\begin{aligned}
& 3\left(\mathrm{M}^{2+}\right)^{\mathrm{VI}}+\mathrm{Si}^{\mathrm{IV}} \Rightarrow \mathrm{Ti}^{\mathrm{VI}}+2 \mathrm{Al}^{\mathrm{IV}}+\square(\text { Ti-Tschermak }) \\
& \text { ou } 2 \mathrm{Al}^{\mathrm{VI}} \Rightarrow \mathrm{Ti}^{\mathrm{VI}}+\left(\mathrm{M}^{2+}\right)^{\mathrm{VI}} \\
& \left(\mathrm{M}^{2+}\right)^{\mathrm{VI}}+\mathrm{Si}^{\mathrm{IV}} \Rightarrow\left(\mathrm{Fe}^{3+}\right)^{\mathrm{VI}}+\mathrm{Al}^{\mathrm{VI}}(\mathrm{Fe}-\text { Tschermak })
\end{aligned}
$$

covita.

$\mathrm{Al}^{\mathrm{VI}}$ e $\mathrm{Fe}^{3+}$ podendo se substituir $\Rightarrow$ ferrimus-

A camada interfoliar pode igualmente ser afetada pela substituição ilítica, conduzindo à pirofilita, conforme equação (7):

$$
\mathrm{K}^{\mathrm{XII}}+\mathrm{Al}^{\mathrm{IV}} \Rightarrow \square^{\mathrm{XII}}+\mathrm{Si}^{\mathrm{IV}}
$$

Observa-se que, assim como a biotita, a muscovita forma soluções sólidas complexas que jamais satisfarão, de maneira restrita, à uma definição cristaloquímica simples.

A substituição fengítica (celadonítica) nas micas brancas do MGSB ocorre de maneiras distintas: (a) em porcentagens de celadonita pelo excesso de sílica em posição tetraédrica: $\mathrm{Si}(\mathrm{x})=\mathrm{Si}-6$ (para 22 oxigênios na fórmula estrutural); (b) visualizada no diagrama binário $\mathrm{Si}+\mathrm{M}^{2+}$ versus $\mathrm{Al}$ total $\left(\mathrm{Al}^{\mathrm{VI}}+\mathrm{Al}^{\mathrm{IV}}\right)$, com M $\mathrm{M}^{2+}$ $=\mathrm{Mg}+\mathrm{Fe}_{t}+\mathrm{Mn}\left(\mathrm{Fe}_{t}\right.$ considerado como $\left.\mathrm{Fe}^{2+}\right)$. As correlações negativas são perfeitamente definidas (Fig. 7) com coeficiente de correlação superior a 0,95 . Contrariamente, as inclinações são diferentes: $-1,00 \pm 0,04$ para as micas dos granitos; $-1,17$ para as micas dos greisens e filões micáceos $(\mathrm{R}=0,956)$ e - 1,29 para as micas das encaixantes $(R=0,899)$. Não obstante, as inclinações diferem pouco daquela correspondente à substituição $\mathrm{Si}+\mathrm{M}^{2+} \rightarrow \mathrm{Al}_{\mathrm{t}}$ (Fig. 7); (c) estimada no diagrama $\mathrm{Al}^{\mathrm{VI}}+\mathrm{Al}^{\mathrm{IV}} / \mathrm{Fe}_{\mathrm{t}}$ (a.f.u.), que representa a parte do $\mathrm{Fe}$ na substituição fengítica (Fig. 8). Define-se, em 3 dos 4 casos, uma relação linear com inclinação variável: granito $(\mathrm{g} 1 \mathrm{a})$, granito $(\mathrm{g} 1 \mathrm{~b})$ e granito $(\mathrm{g} 1 \mathrm{c})$ (inclinação = $-0,49 ; \mathrm{R}=0,479$ ), granito g1d (inclinação $=-0,54, \mathrm{R}$ $=0,868$ ), encaixantes (inclinação $=-0,67, \mathrm{R}=0,755$ ), enquanto que para greisens e filões micáceos a relação é preferencialmente do tipo exponencial $(\mathrm{R}=0,892)$, o que poderia indicar que um outro elemento, além do $\mathrm{Fe}$, estaria interferindo de maneira significativa nesta substituição.

Todas as micas analisadas são fracamente magnesianas e titaníferas. $\mathrm{O} F e$ pode existir sob os dois estados de oxidação, sendo que o grau de oxidação pode ser inferido pelo diagrama $((\mathrm{Si}-3)+\mathrm{Ti}) /(\mathrm{Mg}+\mathrm{Fe})$ (Ramboz 1980, Friedrich 1984), onde o Fe encontra-se inteiramente na forma reduzida e o Ti incorporado em posição tetraédrica (Fig. 9). São possíveis 3 situações, de acordo com a localização das análises com relação à primeira bissetriz, que corresponde à estequiometria: a) sobre ou próximo da primeira bissetriz $(\mathrm{Si}-3)+\mathrm{Ti}$ $=\mathrm{Mg}+\mathrm{Fe}^{2+}{ }_{\mathrm{t}}$. As micas são dioctaédricas e incorporam
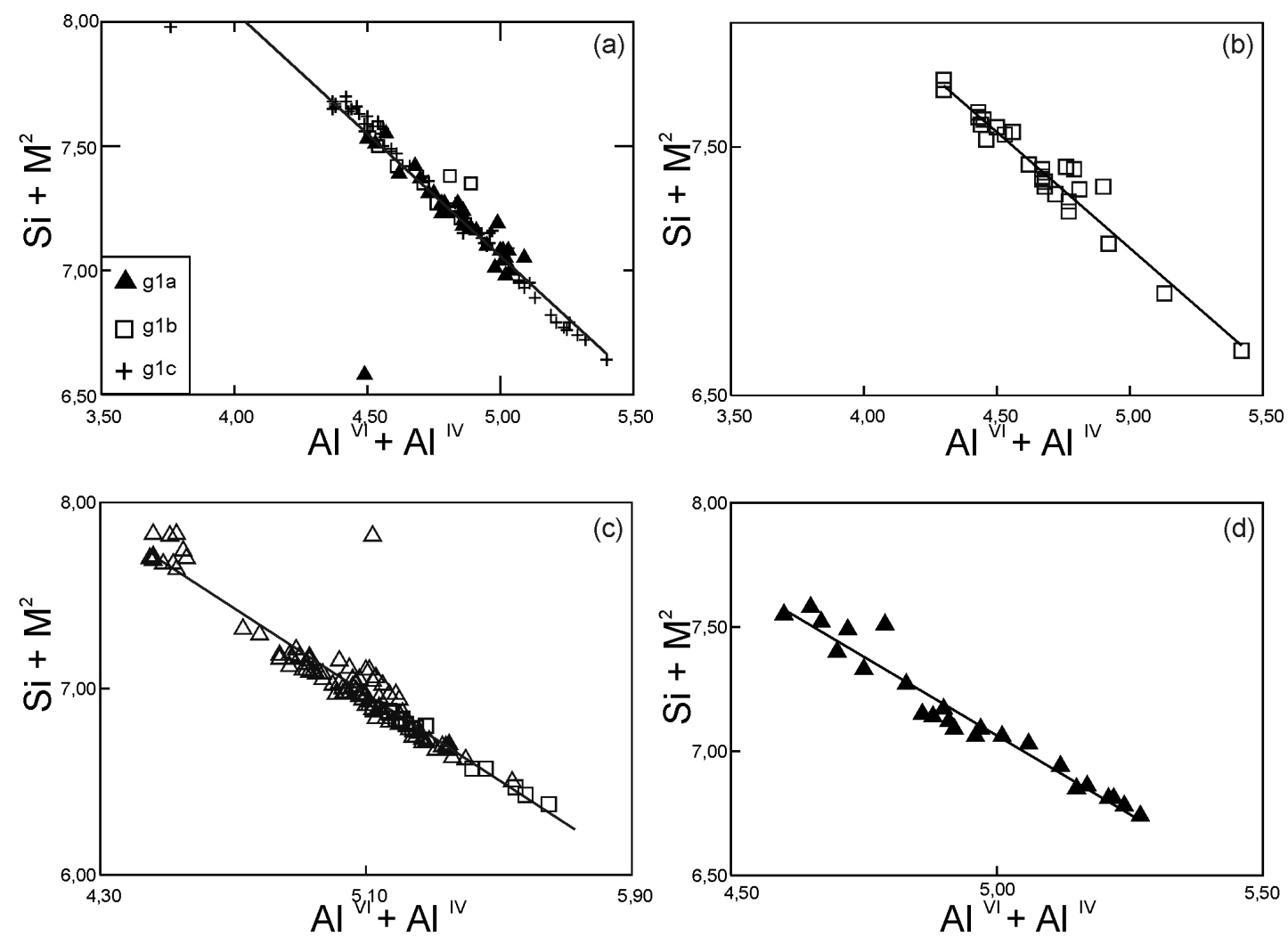

Figura 7 - Substituição fengítica para as associações de micas brancas do MGSB: (a) fácies (gla), (glb) e (glc); (b) fácies (gld); (c) greisens (triângulos) e filões micáceos (quadrados); (d) quartzitos encaixantes. 

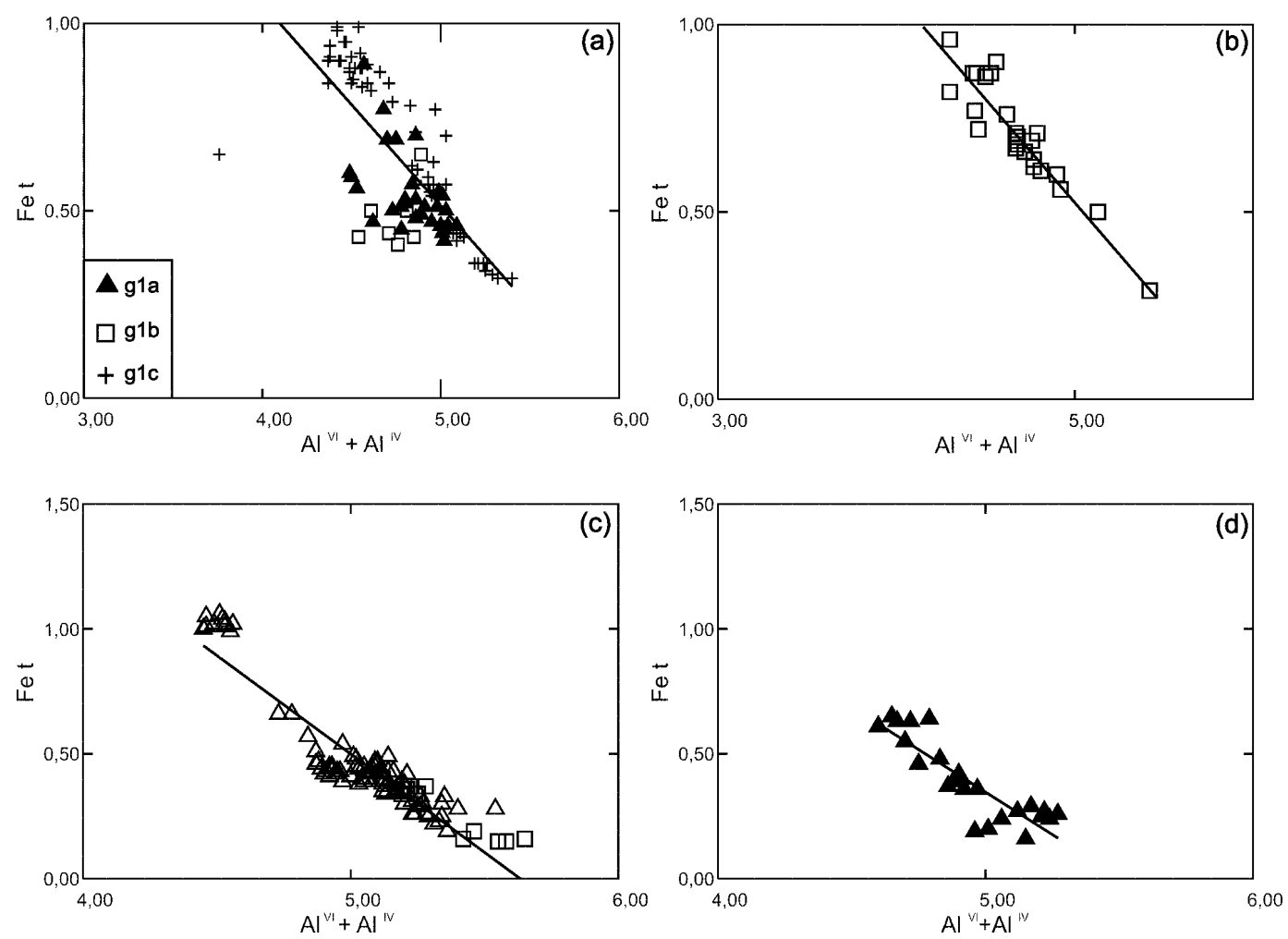

Figura 8 - Correlação entre Al total e Fe (a.f.u) para micas brancas do MGSB: (a) fácies (gla), (glb) e (glc); (b) fácies (gld); (c) greisens (triângulos) e filões micáceos (quadrados); (d) quartzitos encaixantes.
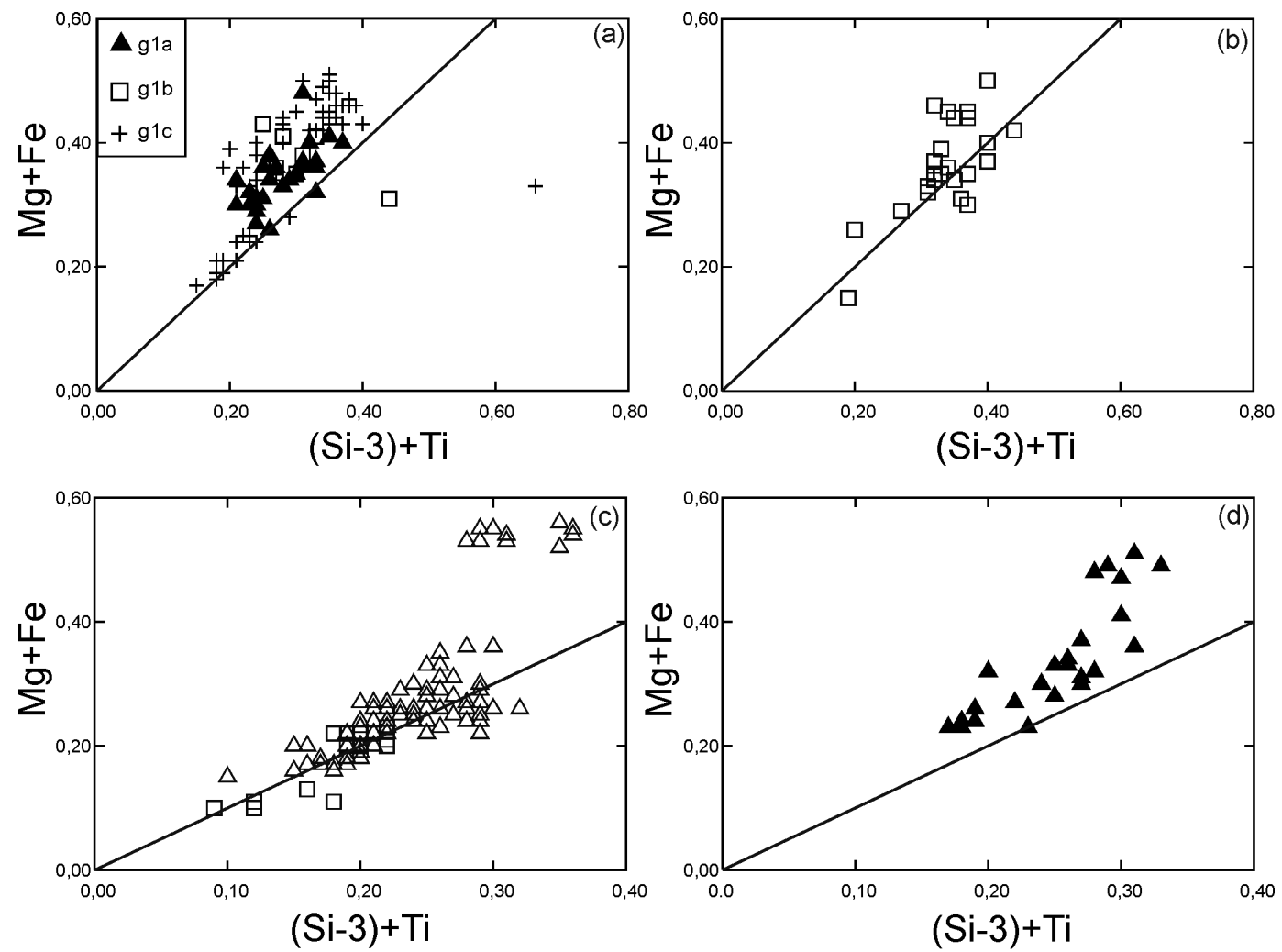

Figura 9 - Diagrama ((Si-3) + Ti)/(Mg + Fe) (Ramboz 1980) para as associações de micas brancas do MGSB: (a) fácies (gla), (glb) e (glc); (b) fácies (gld); (c) greisens (triângulos) e filões micáceos (quadrados); (d) quartzitos encaixantes. Para a construção do gráfico utilizam-se os valores dos parâmetros estruturais divididos por 2. As retas indicam as bissetrizes. 
$\mathrm{Mg}$ e $\mathrm{Fe}$ (inteiramente sob forma divalente) em substituição fengítica; b) acima da primeira bissetriz $(\mathrm{Si}-3)$ $+\mathrm{Ti}<\mathrm{Mg}+\mathrm{Fe}^{2+}$. Apenas parte do $\mathrm{Fe}$ está sob forma divalente, o restante permanecendo trivalente e substituindo $\mathrm{Al}^{\mathrm{VI}} ; \mathrm{c}$ ) abaixo da primeira bissetriz $(\mathrm{Si}-3)+\mathrm{Ti}$ $>\mathrm{Mg}+\mathrm{Fe}^{2+}{ }^{2} \cdot \mathrm{Mg}+\mathrm{Fe}$ inteiramente sob forma divalente. Ocorre excesso de $\mathrm{Al}^{\mathrm{VI}}$ com relação à fengita teórica dioctaédrica $\rightarrow$ excesso de ocupação octaédrica.

A figura 9 mostra a distribuição das micas nos diferentes grupos petrográficos. Micas brancas dos granitos distribuem-se essencialmente acima da bissetriz do diagrama, significando uma proporção não negligenciável de $\mathrm{Fe}$ oxidado; para os demais grupos, as micas encontram-se, preferencialmente, sobre a bissetriz, exceção feita às micas brancas dos quartzitos encaixantes (Fig. 9d).

O comportamento do $\mathrm{Fe}$ pode igualmente ser verificado no diagrama $\mathrm{Al}^{\mathrm{IV}}$ versus $\left(\mathrm{Al}^{\mathrm{VI}}-1\right)+2 \mathrm{Ti}$, levando-se em consideração a substituição possível com Ti (Fig. 10). Aqui a proporção de $\mathrm{Fe}^{3+}$ é significativa para todas as micas brancas do MGSB, independentemente do tipo petrográfico. A figura 11 mostra de maneira evidente a estreita correlação entre o excesso de Si tetraédrico e a compensação octaédrica nos diferentes grupos petrográficos.

A determinação dos teores de Li em micas de granitos e greisens tem importância relevante para o estabelecimento de suas fórmulas estruturais e classi- ficações. Uma vez que esse elemento não é analisado em microssonda eletrônica, uma série de formulações empíricas foi proposta na literatura com vistas à sua obtenção indireta (Foster 1960, Monier \& Robert 1986, Fonteilles 1987, Stone et al. 1988, Henderson \& Martin 1989, Tindle \& Webb 1990). Entretanto, estas fórmulas aplicam-se às micas fortemente litiníferas (lepidolitas s.l.), onde o aumento do caráter litinífero faz-se acompanhar pelo aumento de Si e F em substituição de $\mathrm{OH}$. Para as amostras de micas brancas do MGSB para as quais se dispõem de teores de $\mathrm{Li}_{2} \mathrm{O}$ observa-se boa correlação $(0,963) \mathrm{Li}_{2} \mathrm{O} / \mathrm{SiO}_{2}$ (Tab. 3; Fig. 12).

A correlação $\mathrm{Li}_{2} \mathrm{O} / \mathrm{F}$ é boa, com uma reta $\mathrm{Li}$ $=0,058 \mathrm{~F}-0,0272, \mathrm{R}=0,96$ (Fig. 13a), com $\mathrm{Li}_{2} \mathrm{O}$ e $\mathrm{F}$ obtidos por via úmida. Uma reta com mesma inclinação $\mathrm{Li}=0,054 \mathrm{~F}-0,0122$ e $\mathrm{R}=0,95$ (Fig. 13b) pode ser traçada a partir dos valores de $\mathrm{Li}_{2} \mathrm{O}$ obtidos por via úmida e F obtido em microssonda eletrônica. Estas duas retas de correlação são bastante distintas daquela estabelecida por Charoy et al. (1995) para termos litiníferos $\left(\mathrm{Li}_{2} \mathrm{O}\right.$ $=0,83 \mathrm{~F})$. É necessário destacar que o número de análises de Li é baixo e que a origem das micas analisadas é bastante distinta, o que torna delicada toda e qualquer generalização para a correlação estabelecida entre Li e $\mathrm{F}$.

Monier (1985) estabelece a anticorrelação entre a substituição paragonítica e a substituição fengítica, valorizando a importânica de XFe sobre a inclinação desta anticorrelação. A análise das micas brancas (Tab.

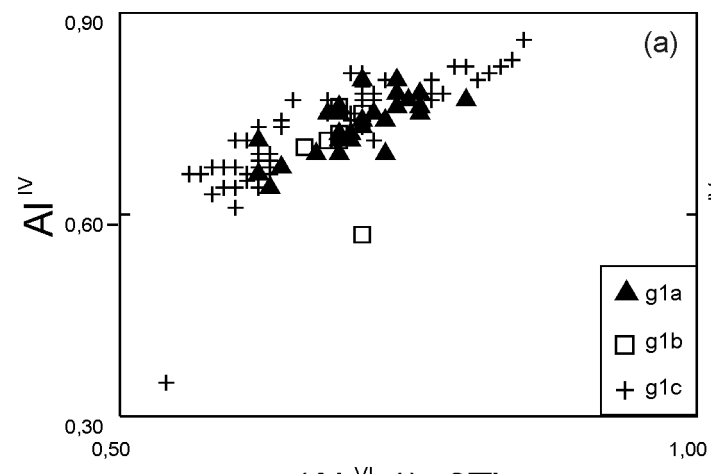

$\left(\mathrm{Al} \mathrm{I}^{\mathrm{v}}-1\right)+2 \mathrm{Ti}$

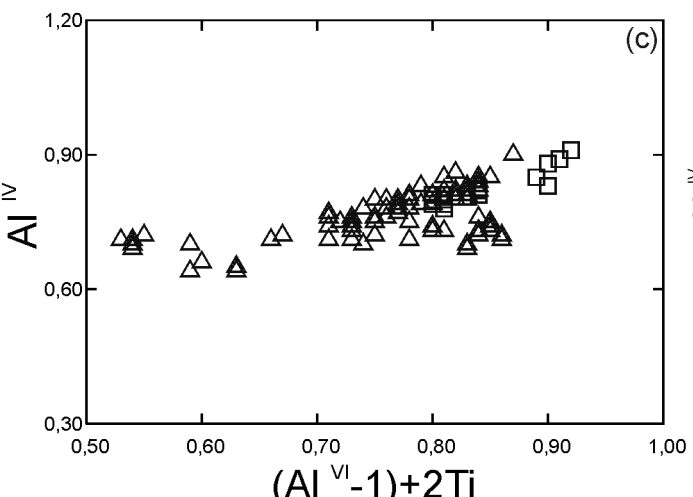

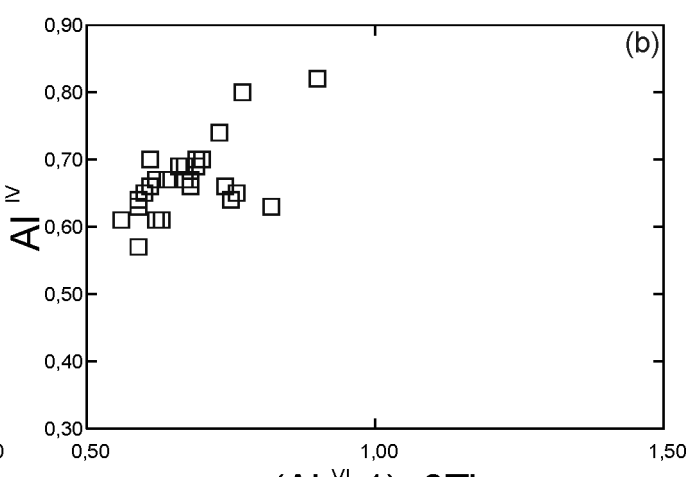

$\left(A I^{\mathrm{v}}-1\right)+2 \mathrm{Ti}$

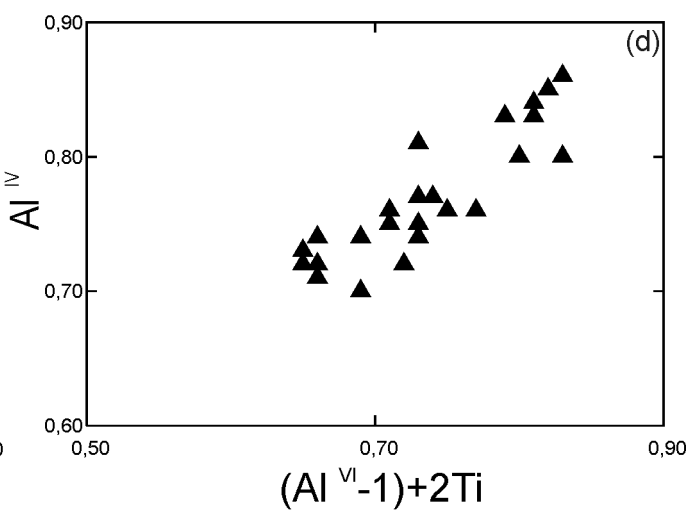

Figura 10 - Diagrama $A I^{V} /\left(A l^{V I}-1\right)+2 T i$ para micas brancas do MGSB e encaixantes. (a) fácies ( $(\mathrm{lla})$, ( $\mathrm{glb}$ ) e ( $\mathrm{glc}$ ); (b) fácies ( $\mathrm{gld}$ ); (c) greisens (triângulos) e filões micáceos (quadrados); (d) quartzitos encaixantes. Para a construção do gráfico utilizam-se os valores dos parâmetros estruturais divididos por 2. 

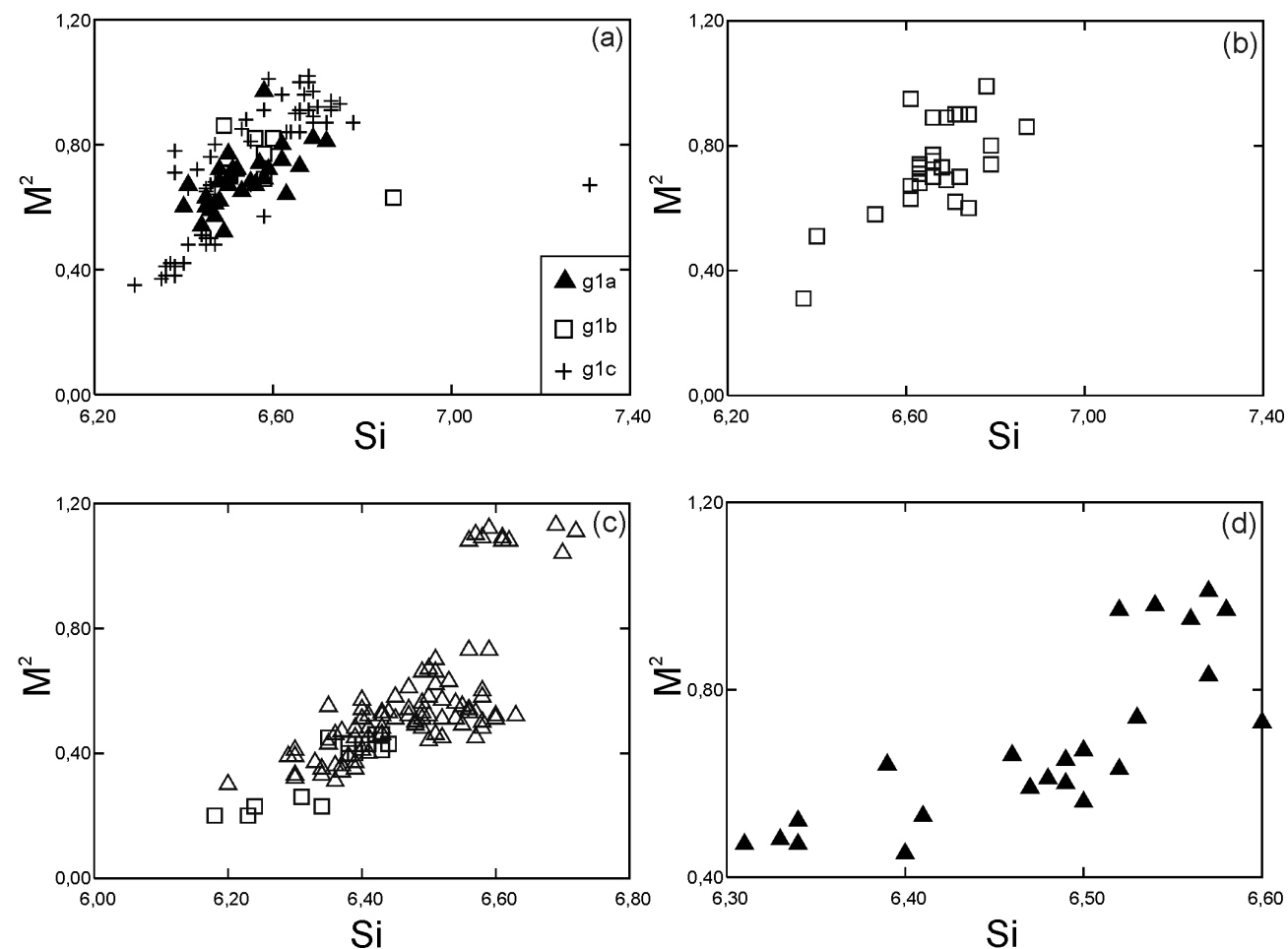

Figura 11 - Substituição $M^{2+} / S i$ (a.f.u.) para micas brancas do MGSB: (a) fácies (gla), (glb) e (glc); (b) fácies (gld); (c) greisens (triângulos) e filóes micáceos (quadrados); (d) quartzitos encaixantes.

Tabela 3 - Análises químicas por via úmida e microssonda eletrônica de micas brancas de fácies graniticas (SBC-67A e SBC-52 = fácies g1c), filões micáceos (SBC-08 e SBC-76) e greisen $(S B-61 A)$ do MGSB. n.a = não analisado. $F^{*}=$ média dos valores de $F$ obtidos em microssonda eletrônica.

\begin{tabular}{c|c|c|c|c|c}
\hline Li $(\mathrm{ppm})$ & $\mathrm{Li}(\mathrm{ppm})$ & $\mathrm{Li} 2 \mathrm{O}(\%)$ & $\mathrm{SiO} 2(\%)$ & $\mathrm{F}(\%)$ & $\mathrm{F} *(\%)$ \\
\hline SBC-67A & 613 & 0,131 & 48,06 & n.a. & 2,49 \\
\hline SBC-52 & 712 & 0,153 & 47,98 & 3,10 & 3,08 \\
\hline SBC-08 & 198 & 0,042 & 46,78 & 1,40 & 0,94 \\
\hline SBC-76 & 56 & 0,012 & 46,21 & 0,80 & 0,80 \\
\hline SB-61A & 251 & 0,054 & 47,00 & 1,10 & 0,90 \\
\hline
\end{tabular}

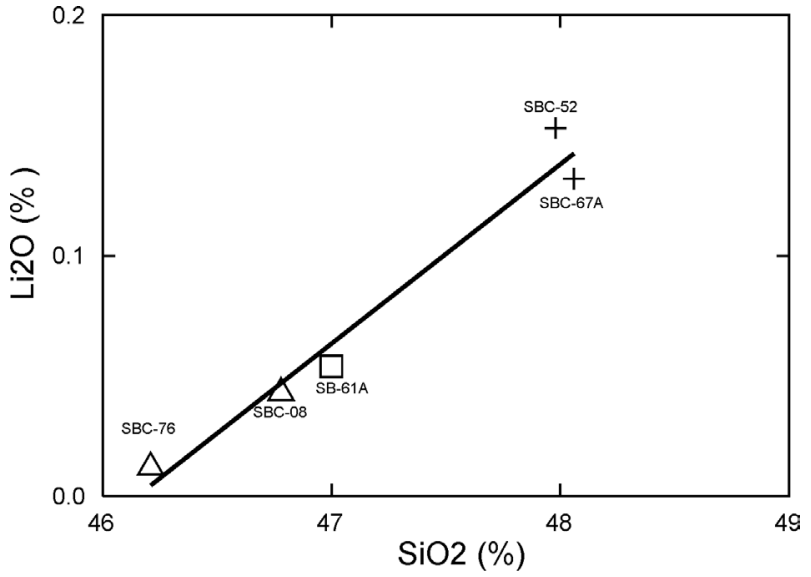

Figura 12 - Correlação $\mathrm{SiO}_{2}$ versus $\mathrm{Li}_{2} \mathrm{O}$ para micas brancas das fácies graníticas ( $S B C-67 A$ e $S B C$ - 52 = fácies glc), filóes micáceos ( $S B C-08$ e $S B C$ - 76) e greisen ( $S B$ - 61A) do MGSB.
2) mostra que a proporção de $\mathrm{Na}$ em posição interfoliar é secundária e bastante variável no interior de um mesmo grupo de micas semelhantes (fissuras, inclusões em plagioclásio, agregados com biotita, intersticiais, etc.). A substituição paragonítica (quantificada pela razão em porcentagem de $\mathrm{Na} / \mathrm{Na}+\mathrm{K}$ ) encontra-se entre 2 e $5 \%$; as micas dos quartzitos encaixantes mostram-se estatisticamente menos sódicas.

Na substituição ilítica a diminuição dos cátions interfoliares é acompanhada pelo crescimento do Si tetraédrico (às expensas de $\mathrm{Al}^{\mathrm{IV}}$ ). Algumas análises mostram forte déficit em álcalis (X int. $=1,50$ a 1,80$)$ sem que se note aumento significativo em Si. Duas análises de mica intersticial mostram-se quase desprovidas de álcalis sem que, entretanto, a razão $\mathrm{Si}^{\mathrm{IV}} / \mathrm{Al}^{\mathrm{VI}}$ atinja aquela correspondente à pirofilita. Tal "lixiviação" dos álcalis poderia significar a expressão de alteração à baixa temperatura, conduzindo a termos argilosos "mais 

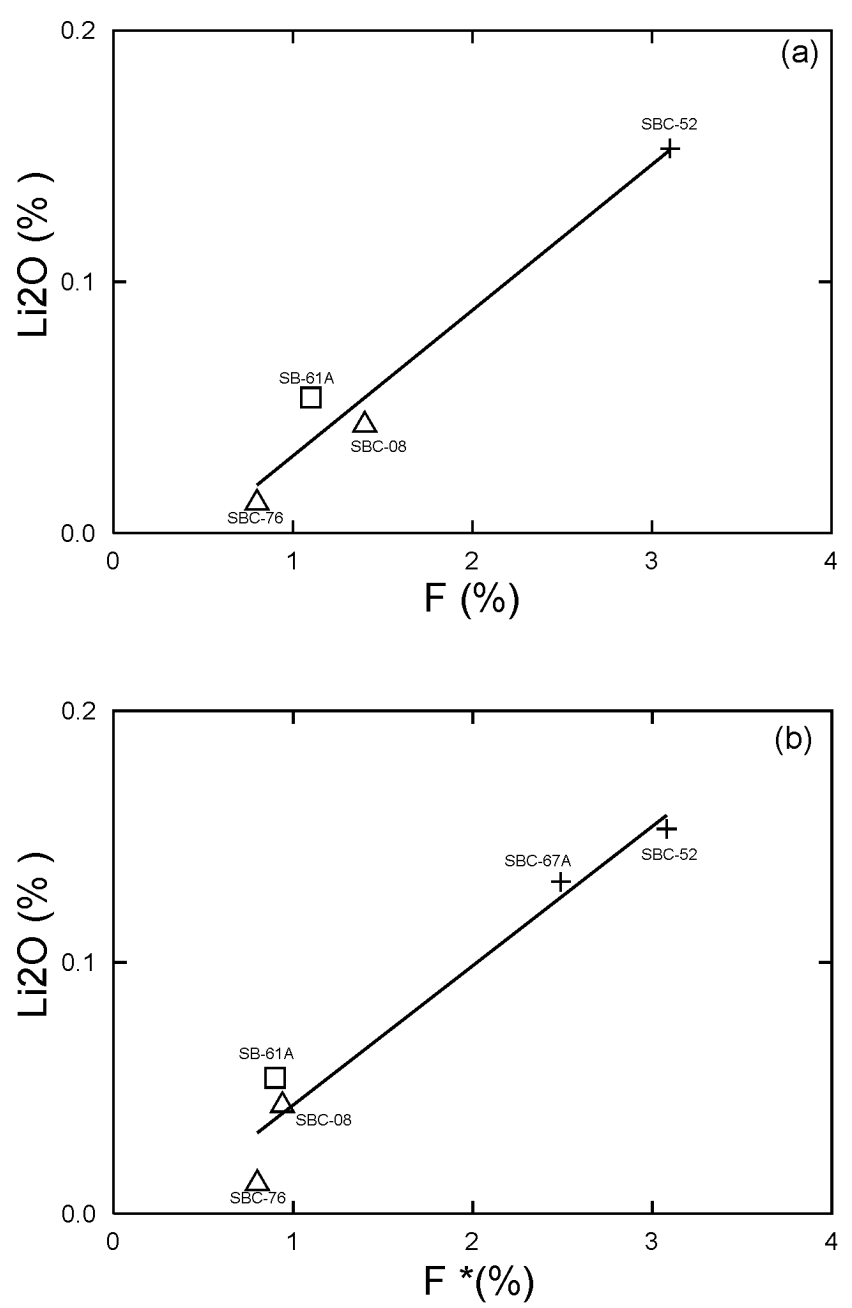

Figura 13 - Correlação Li, O/F para micas brancas do $M G S B$. a) $\mathrm{Li}_{2} \mathrm{O}$ e F obtidos por via úmida; b) F representa a média dos resultados obtidos em microssonda eletrônica e Li por via úmida. Triângulo = filões micáceos; quadrado $=$ greisens; cruz $=$ fácies $(\mathrm{glc})$.

degradados".

DISCUSSÕES E CONCLUSÕES A identificação de micas de origem magmática nas rochas do MGSB foi dificultada pelos processos hidrotermais a que essas rochas foram submetidas. Com relação à biotita, podese afirmar que em todas as amostras analisadas esta mica mostra sinais de reequilíbrio tardio, com formação de minerais de $\mathrm{Fe}$ e/ou Ti distribuídos ao longo das superfícies de clivagens. Os teores de $\mathrm{TiO}_{2}$, bem como a razão $\mathrm{FeO} / \mathrm{MgO}$ e Ti (a.f.u.) mostrados na tabela 1, situam a biotita associada às fácies graníticas do MGSB no campo de biotita de origem metassomática estabelecido por Botelho (1992) para o granito Pedra Branca, situado na Sub-província Paranã, em Goiás. No granito (g1c), a biotita inclusa em quartzo mostra quimismo semelhante à biotita das fácies onde essa mica ocorre em proporções modais significativas (gla e glb), com teores de $\mathrm{FeO}$ próximos aos da fácies (g1a) e os de $\mathrm{Ti}$ inferiores aos das demais fácies. Ti (a.f.u) nesta biotita apresenta os mais baixos valores. Essa mica aparenta ser, paradoxalmente, a mais perturbada metassomatica- mente.

Biotita em rochas ígneas é, de maneira geral, hóspede do alumínio excedente (Al estequiométrico na fórmula de feldspatos). Al total ( $\left.\mathrm{Al}^{\mathrm{IV}} \mathrm{e}^{\mathrm{Al}}{ }^{\mathrm{VI}}\right)$ varia com a paragênese em equilíbrio e aumenta segundo a seqüência clinopiroxênio - anfibólio - biotita - muscovita, cordierita, silicato de Al. Paralelamente a este aumento de $\mathrm{Al}$, ocorre igual aumento de $\mathrm{XFe}(\mathrm{Fe} / \mathrm{Fe}$ $+\mathrm{Mg}$ ), de acordo com Foster (1960) e Albuquerque (1973), mas contrariamente ao observado por Guidotti et al. (1975).

$\mathrm{O}$ mecanismo dominante que permite o enriquecimento em $\mathrm{Al}$ na biotita é a substituição do tipo Al-Tschermak: $\left(\mathrm{R}^{2+}\right)^{\mathrm{VI}}+\mathrm{Si}^{\mathrm{IV}} \Leftrightarrow \mathrm{Al}^{\mathrm{IV}}+\mathrm{Al}^{\mathrm{VI}}$, religando os termos extremos flogopita - annita - eastonita - siderofilita. Foster (1960) sugere igualmente a seguinte substituição: $3\left(\mathrm{R}^{2+}\right)^{\mathrm{VI}} \Leftrightarrow 2 \mathrm{Al}^{\mathrm{VI}}+(\square)^{\mathrm{VI}}$, que garante a ligação estrutural biotita - muscovita.

As substituições Fe, Mg e Mn podem ser simples em nível da camada octaédrica. Ti pode igualmente ser incorporado na biotita, mas sua carga e o raio iônico dificultam a substituição (Harrison 1990). Os álcalis

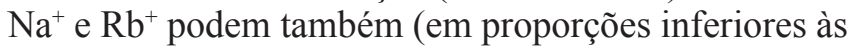
observadas em muscovita) substitutir $\mathrm{K}^{+}$interfoliar. $\mathrm{F}$ e $\mathrm{Cl}$ podem substituir o radical $\mathrm{OH}$.

No MGSB, a biotita de cada fácies petrográfica (exceção daquela da fácies g1c) posiciona-se segundo dois campos com $\mathrm{Al}$ total fracamente crescente e $\mathrm{Mg}$ extremamente variável. Tal fato poderia corresponder à evolução própria de cada fácies, com os termos magnesianos menos evoluídos, mas que não é corroborado pelo comportamento do Ti, não correlacionável ao $\mathrm{Mg}$. Esta dualidade no comportamento químico da biotita é certamente devida à alteração geral que, de maneira intensa, mas anisotrópica e heterogênea, modificou sua composição, essencialmente pela troca $\mathrm{Fe} \Leftrightarrow \mathrm{Mg}$.

Ao se considerar as relações existentes entre $\mathrm{Mg}$, Ti e Al total da biotita das fácies graníticas do MGSB, não parece existir filiação genética no sentido granito (g1a) $\Rightarrow$ granito (g1b) granito (g1c). Não obstante, dados petrográficos, químicos, geocronológicos e microtermométricos apontam para a atuação de importantes perturbações térmicas e deformacionais associadas ao evento orogenético Brasiliano e que foram responsáveis pela abertura do sistema das micas, denotando a importância de uma fase fluida atuante após a alteração hidrotermal e mineralização. A superimposição do evento orogenético Brasiliano marca-se, no MGSB, pela intensa deformação a que as fácies graníticas e greisens foram submetidas e pode ser confirmada por dados geocronológicos K/Ar obtidos em muscovita. Os resultados fornecem idades que variam entre 504 e 540 $\mathrm{Ma}$, contrariamente às idades $\mathrm{U} / \mathrm{Pb}$ obtidas em monazita, que situam-se entre 1,14 e 1,35 Ga (Pinto-Coelho 1996). Análises microtermométricas realizadas em inclusões fluidas dos granitos e rochas hidrotermalizadas associadas ao MGSB (Pinto-Coelho \& Moura 2006) mostram que as inclusões primárias encontradas em feldspato alcalino de cristalização precoce nas fácies (g1a) e (g1c) apresentam baixos valores de tempera- 
tura de homogeneização total e salinidade, sugerindo que essas porções não contêm mais o fluido magmático aprisionado, mas fluidos resultantes de resfriamento progressivo ou de alteração hidrotermal.

A caracterização de muscovita de origem magmática é amplamente debatida na literatura especializada. De acordo com Miller et al. (1981), Bailey (1984), Speer (1984) e Borodina \& Fershtater (1988), muscovita primária é aquela que apresenta as seguintes características: (a) cristais relativamente grandes quando comparados aos de outras fases primárias presentes na mesma rocha; (b) cristais com contornos bem definidos, automorfos a subautomorfos; (c) não associação direta com outros minerais a partir dos quais essa mica poderia se formar, e (d) presença em rochas com textura claramente magmática.

O teor em Ti é um critério químico comumente utilizado para caracterização da muscovita primária. Zen (1988) sugere que teores a partir de $0,6 \% \mathrm{TiO}_{2}$ sejam indicativos de muscovita com origem magmática. Monier \& Robert (1986) descrevem muscovita magmática com teores de $\mathrm{TiO}_{2}$ entre 0,33 e $2,28 \%$, onde as variações são devidas a zoneamento centro/borda do cristal, sendo o centro mais rico em Ti.

Em nenhuma das fácies graníticas do MGSB foi identificada a presença de muscovita primária, conforme critérios texturais e químicos estabelecidos pelos autores acima mencionados. Independentemente do hábito, origem ou disposição textural, estas micas apresentam um caráter fengítico acentuado, sendo pobres em Mg, Ti, $\mathrm{Na}$ e Li. Teores de $\mathrm{TiO}_{2}$ variam entre 0,05 - 0,30\% (granito g1a), 0,02 - 0,45 (granito g1b), entre $0,03-0,26 \%$ (granito g1c) e entre $0,02-0,18 \%$ (granito g1d), não sendo raras as concentrações abaixo do limite de detecção. Não foram observadas variações importantes no comportamento de micas brancas de granitos, greisens ou mesmo filões micáceos.

Contrariamente a outros granitos da Província Estanífera de Goiás, como o Maciço Mangabeira (Moura \& Botelho 1994, 2000), onde micas litiníferas ocorrem em granitos, pegmatitos e rochas metassomáticas associadas, o MGSB parece constituir um sistema pouco litinífero. Análises químicas obtidas em rocha total desses granitos (Pinto-Coelho 1996) revelam valores de Li que variam entre 17 - 34 ppm (granito g1a), 20 - 23 ppm (granito g1b), 16 - 140 ppm (granitos g1c e g1d).

A boa correlação positiva $(0,963)$ entre $\mathrm{SiO}_{2}$ e $\mathrm{Li}_{2} \mathrm{O}$ em mica branca mostrada na figura 12 explica-se pelo fato de que em micas tri-octaédricas ocorre aumento de $\mathrm{Si}$, diminuição de $\mathrm{Al}^{\mathrm{V}}$ e $\mathrm{Fe}^{2+}$ com o aumento de $\mathrm{Li}$ (Stone et al. 1988). Não obstante os baixos valores em Li obtidos por via úmida e o número pouco representativo de amostras analisadas (Tab. 3), pode-se supor a presença de uma fase litinífera tardia do tipo protolitionita ou zinwaldita para explicar o caráter anômalo de uma amostra de mica branca de greisen que apresenta teores de $\mathrm{Fe}$, $\mathrm{Li}$ e $\mathrm{Rb}(11,06 \% \mathrm{FeO} ; 5.240$ ppm Li e $5.277 \mathrm{ppm} \mathrm{Rb}$ ) anormalmente elevados.

A mica branca do quartzito encaixante não apresenta nenhuma assinatura particular.

No MGSB existem diversas gerações de mica branca que, entretanto, não seguem uma evolução caracterizada no âmbito das diversas substituições possíveis, à exceção de uma tendência ao aumento das lacunas interfoliares. A assinatura original das micas di e tri-octaédricas do maciço teria sido obliterada pela intensidade das alterações hidrotermais aí atuantes.

Agradecimentos Aos revisores anônimos da Revista Brasileira de Geociências pelas valiosas críticas e sugestões apresentadas.

\section{Referências}

Abdel-Rahman A.M. 1994. Nature of biotites from alkaline, calc-alaline, and peraluminous magmas. Journ. Petrol., 35:525-541.

Albuquerque C.A.R. 1973. Geochemistry of biotites from granites rocks, Northern Portugal. Geochim. Cosmochim. Acta, 37:1779-1802.

Andrade G.F. de 1978. As mineralizações de estanho, berílio e cobre do granito da Serra Branca, Cavalcante - Goiás. Brasília, Dissertação de Mestrado, Universidade de Brasília, $83 \mathrm{p}$.

Bailey S.W. 1984. Classification and structures of the micas. In: S.W. Bailey (ed.) Micas. Review in Mineralogy. 13, Washington, Mineralogical Society of America, p. 1-12.

Barrière M., Cotten, J. 1979. Biotites and associated minerals as markers of magmatic fractionation and deuteric equilibration I granites. Contr. Mineral. Petrol., 70:183-192.

Bilal E. 1991. Etude de deux massifs de la province stannifère de l'Etat de Goiás (Brésil) et des formations métassomatiques associées aux minéralisations em $\mathrm{Sn}$ et Be. Tese de Doutoramento, Université de St. Etienne, 382 p.
Borodina N.S \& Fershtater G.B. 1988. Composition and nature of muscovites in granites. Internat. Geol. Rev., 30:375-381

Botelho N.F. 1992. Les ensembles granitiques subalcalins a peralumineux minéralisés en Sn et In de la sous-province Paranã, Etat de Goiás, Brésil. Paris, Tese de Doutoramento, Paris VI, 344 p.

Bray E.A. 1994. Compositions of micas in peraluminous granitoids of the eastern Arabian Shield. Contr. Mineral. Petrol., 116:381-397.

Charoy B., Chaussidon M., Noronha F. 1995. Lithium zonation in white micas from Argemela microgranite (central Portugal): an in-situ ion-electron-microprobe and spectroscopic investigation. Eur. J. Mineral., 7:335-352.

Deer W.A., Howie R.A. \& Zussman J. 2000. Minerais constituintes das rochas - uma introdução. Lisboa, Fundação Calouste Gulbenkian, 727 p.

Fernandes C.M.D., Teixeira N.P., Borges R.M.K., Bettencourt J.S. 2006. Química mineral da muscovita de rochas graníticas e greisens da Suíte Intrusiva Velho Guilherme, 
Província Estanífera do Sul do Pará. Rev. Bras. Geoc., 36 (1 - Suplemento):26-33.

Fonteilles M. 1987. La composition chimique des micas lithinifères (et autres minéraux) des granites d'Echassières comme image de leur évolution magmatique. Bull. B.R.G.M. Géol. Fr., 2-3:149-178.

Foster M.D. 1960. Interpretation of the composition of trioctahedral micas. U.S. Geol. Surv. Prof. Paper 354-B:149.

Friedrich M. 1984. Le complexe granitique hyperalumineux de St. Sylvestre, nord-ouest du Massif Central Français. Nancy, Tese $3^{\text {ème }}$ Cycle, $361 \mathrm{p}$.

Garcia D. \& Fonteilles M. 1985. Évolution du chimisme des biotites et des muscovites dans une série de granitoïdes (Nord Portugal): imlications pétrologiques et métallogéniques. C.R. Acad. Sci. Paris, 301:819-822.

Guidotti C.V. 1978. Muscovite and K-feldspar from two-mica adamellite in Northwestern Maine: composition and petrogenetic implications. Amer. Mineral., 63:750-753.

Guidotti C.V., Cheney J.T., Conatore P.D. 1975. Interrelationship between $\mathrm{Mg} / \mathrm{Fe}$ ratio and octahedral $\mathrm{Al}$ content in biotite. Amer. Mineral., 60:849-853.

Harrison T.N. 1990. Chemical variation in micas from the Cairngorm pluton, Scotland. Mineral. Mag., 54:355366.

Henderson C.M.B. \& Martin J.S. 1989. Compositional relations in Li-micas from SW England and France: an ionand electron-microprobe study. Mineral. Mag., 53:427449.

Le Maître R.W., Batemman P., Dudek A., Keller J., Lameyre J., Le Bas M.J., Sabine P.A., Schmidt R., Sorensen H., Streckeisen A., Wooley; R.A., Zannettin B. 1989. A classification of igneous rocks and glossary of terms. Recommendation of the International Union of Geological Sciences. Subcommission on the Systematics of Igneous Rocks. Oxford, UK, Blackwell Scientific Publications, $193 \mathrm{p}$.

Marini O.J. \& Botelho N.F. 1986. A Província Estanífera de Goiás. Rev. Bras. Geoc., 22:8-19.

Miller C.F., Stoddard E.F., Bradfish L.J., Dollase, W.A. 1981. Composition of plutonic muscovite: genetic implications. Can. Mineral., 19:25-34.

Monier G. 1985. Cristallochimie des micas des leucogranites - Nouvelles données expérimentales et applications pétrologiques. Nancy, Tese $3^{\text {ème }}$ Cycle (Géol. Géochim. Uranium, Mém. Nancy, 14), 347 p.

Monier G., Charoy B., Cuney M., Ohnenstetter D., Robert J.L. 1987. Évolution spatiale et temporelle de la composition des micas du granite albitique à topaze-lépidolite de Beauvoir. Géol. de la France, 2-3:179-188.

Monier G. \& Robert J.L. 1986. Evolution of the miscibility gap between muscovite and biotite solid solutions with increasing lithium content: an experimental study in the system $\mathrm{K}_{2} \mathrm{O}-\mathrm{Li}_{2} \mathrm{O}-\mathrm{MgO}-\mathrm{FeO}-\mathrm{Al}_{2} \mathrm{O}_{3}-\mathrm{SiO}_{2}-\mathrm{H}_{2} \mathrm{O}-\mathrm{HF}$ at $600^{\circ} \mathrm{C}, 2 \mathrm{Kbar} P_{\mathrm{H} 2 \mathrm{O}}$ : comparison with natural lithium micas. Mineral. Mag., 50: 641-651.

Monier G. \& Robert J.L. 1986a. Muscovite solid solutions in the system $\mathrm{K}_{2} \mathrm{O}-\mathrm{MgO}-\mathrm{FeO}-\mathrm{Al}_{2} \mathrm{O}_{3}-\mathrm{SiO}_{2}-\mathrm{H}_{2} \mathrm{O}$ : an experimental study at $2 \mathrm{Kbar} P_{\mathrm{H} 2 \mathrm{O}}$ and comparison with natural Li-free white micas. Mineral. Mag., 50:257-266.
Moura M.A. \& Botelho N.F. 1994. Estudo de micas litiníferas e sua importância para a caracterização das rochas da zona greisenizada principal do maciço estanífero Mangabeira, GO. Bol. Geoc. Centro-Oeste, 17:39-48.

Moura M.A. \& Botelho N.F. 2000. The topaz-albite granite and related rocks from the Sn-In mineralized zone of Mangabeira Granitic Massif (GO, Brasil). Rev. Bras. Geoc., 30:270-273.

Nachitt H., Razafimahefa N., Stussi J.M., Carron J.P. 1985. Composition chimique des biotites et typologie magmatique des granitóides. C. R. Acad. Sci. (Paris), Ser. II, 301:810-818.

Nockolds S. 1947. The relation between chemical composition and parageneses in the biotite micas of igneous rocks. Amer. J. Sci., 245:401-420.

Pinto-Coelho C. 1996. Evolution magmatique et hydrothermale du Massif granitique de Serra Branca - Etat de Goiás - Brésil: définition des processus d'altération post-magmatique en liaison avec les minéralisations en $\mathrm{Sn}$, Be et F. Nancy, Tese de Doutoramento, Institut National Polytechnique de Lorraine, $271 \mathrm{p}$.

Pinto-Coelho C., Botelho N.F., Roger G. 1999. Mobilité des terres rares au cours des altérations hydrothermales: l'exemple du granite de Serra Branca- Brésil Central. C.R. Acad. Sci. Paris, 328:663-670.

Pinto-Coelho C.V. \& Moura M.A. 2006. Mineralizações de Sn do Maciço Granítico Serra Branca, Goiás: evolução do sistema hidrotermal e fonte dos fluidos. Rev. Bras. Geoc., 36:157-168.

Ramboz C. 1980. Géochimie et étude des phases fluids de gîsements et indices d'étain-tungstène du Sud du Massif Central (France). Nancy, Tese 3ème Cycle, Institut National Polytechnique de Lorraine. 278 p.

Robert J-L., Beny J-M., Della Ventura G., Hardy M. 1993. Fluorine in micas: crystal-chemical control of the $\mathrm{OH}-\mathrm{F}$ distribution between trioctahedral and dioctahedral sites. Eur. J. Mineral., 5:7-18.

Speer J.A. 1984. Micas in igneous rocks. In: S.W. Bailey (eds.) Micas. Review in Mineralogy, 13, Washington, Mineralogical Society of America, p. 299-356.

Stone M., Exley C.S., George, M.C. 1988. Compositions of trioctahedral micas in the Cornubian batholith. Mineral. Mag., 52:175-192.

Tindle A.G. \& Webb P.C. 1990. Estimation of lithium contents in trioctahedral micas using microprobe data: application to micas from granitic rocks. Eur. J. Mineral., 2:595-610.

Wilhelm S. 1977. Etude minéralogique des feldspaths en relation avec leur contexte géologique (héritage magmatique et rôle des phénomenes thérmiques dans la formation des microtextures). Paris, Tese 3ème Cycle, Université Pierre et Marie Curie. 374 p.

Zen E. 1988. Phase relations of peraluminous granitic rocks and their petrogenetic implications. Ann. Rev. Earth Planet. Sci., 16:21-51.

Manuscrito AE 062/2006

Submetido em 12 de dezembro de 2006 Aceito em 14 de fevereiro de 2008 